This PDF is a selection from a published volume from the National Bureau of Economic Research

Volume Title: Asset Prices and Monetary Policy

Volume Author/Editor: John Y. Campbell, editor

Volume Publisher: University of Chicago Press

Volume ISBN: 0-226-09211-9

Volume URL: http://www.nber.org/books/camp06-1

Conference Date: May 5-6, 2006

Publication Date: September 2008

Chapter Title: Inflation Illusion, Credit, and Asset Prices

Chapter Author: Monika Piazzesi, Martin Schneider

Chapter URL: http://www.nber.org/chapters/c5371

Chapter pages in book: (p. 147 - 189) 


\title{
Inflation Illusion, Credit, and Asset Prices
}

\author{
Monika Piazzesi and Martin Schneider
}

\subsection{Introduction}

Modigliani and Cohn (1979) argue that investors who suffer from inflation illusion price assets as if real payoffs are discounted at the nominal interest rate. They use this idea to rationalize the stock market slump of the 1970s, which coincided with high inflation and high nominal interest rates. More recently, inflation illusion has again become a prominent theme in the financial press because the 2000 s housing boom coincides with low inflation and low nominal interest rates. ${ }^{1}$ However, an early critique of the inflation illusion hypothesis (Summers 1983) points out that the 1970s saw a housing boom coincide with high nominal interest rates. International evidence presented in the following points to a more general stylized fact: in many countries, house-price booms occurred in the high-inflation 1970s and further - typically stronger-booms occurred in the more recent lowinflation environment.

Monika Piazzesi is a professor of finance and the John Huizinga Faculty Fellow at the Graduate School of Business, University of Chicago, and a research associate of the National Bureau of Economic Research. Martin Schneider is an assistant professor of economics at New York University, and a faculty research fellow of the National Bureau of Economic Research.

For comments and suggestions, we thank Olivier Blanchard, Markus Brunnermeier, John Campbell, Martin Feldstein, and participants at the NBER Asset Pricing and Monetary Policy Preconference in November 2005 and the Conference in May 2006. We also thank Pedro Gete for excellent research assistance. The views expressed herein are those of the authors and not necessarily those of the Federal Reserve Bank of Minneapolis or the Federal Reserve System.

1. For example, see Pam Woodall's survey on world property markets in the Economist on March 29, 2003. The article "Castles in Hot Air" in this report and an earlier article, "Going through the Roof" in the Economist on March 28, 2002, argue that inflation illusion fuels the recent house-price boom. 
In this chapter, we consider the effect of inflation illusion on asset prices in a general equilibrium model with heterogeneous agents. The key assumptions are that (1) agents who suffer from inflation illusion interact with "smart" agents in markets for nominal credit instruments, and (2) borrowing must be backed by real estate. We show under these assumptions that nominal interest rates move with smart agents' inflation expectations, and housing booms occur whenever these expectations are either especially high or low. Moreover, the housing boom is stronger when credit markets are more developed, which suggests that recent financial development may have increased the potential for inflation illusion to drive house prices.

We are led to consider investor heterogeneity because we want our model to account for movements in nominal interest rates. In the data, nominal rates comove with measures of expected inflation, which suggests that at least some investors are aware of the distinction between real and nominal rates. For example, even if stock prices were low in the high inflation 1970s because illusionary investors were discounting at high nominal rates, someone must have also priced high inflation expectations into nominal rates. In our model, there are smart investors who understand the Fisher equation: bond returns are given by the nominal interest rate minus expected inflation. At the same time, there are illusion investors who believe that all changes in nominal rates reflect changes in real interest rates. The equilibrium nominal interest rate then moves - typically less than one for one-with changes in smart investors' inflation expectations.

The key effect in the model is that illusionary and smart investors disagree about real interest rates when smart investors' inflation expectations are either especially high or low. In either case, disagreement generates increased borrowing and lending among households as well as a house-price boom. To see how disagreement about real rates obtains, assume first that smart investors' inflation expectations rise above the historical mean and thus drive up nominal interest rates. Illusionary investors attribute any increase in nominal rates to an increase in real rates. As a result, they end up perceiving higher real rates than smart investors. In contrast, if smart investors have unusually low inflation expectations and drive down nominal rates, illusionary investors perceive lower real rates than smart investors.

Disagreement about real interest rates generates house-price booms if borrowing must be backed by real estate. Indeed, increased credit market activity raises the demand for collateral, which in turn drives up house prices. More specifically, our model generates two scenarios for a housing boom, illustrated in figure 4.1. The scenarios differ in which group of households perceives lower real rates and thus drives up house prices. In a low inflation environment, such as the 2000 s, the increased demand for housing and mortgages is due to illusionary agents, who mistake low nominal rates for low real rates, while smart investors are happy to invest in bonds. In times of high expected inflation, such as the 1970s, the roles of 


$\begin{array}{ccc}\text { 1970s } & \text { expect high inflation } & \\ \text { (high nominal rate) } & \text { perceive low real rate } & \text { perceive high real rate } \\ \text { 2000s } & \text { borrow and buy houses } & \\ \text { expect low inflation } & \\ \text { (low nominal rate) } & \text { perceive high real rate } & \text { perceive low real rate }\end{array}$

Fig. 4.1 Housing booms under different inflation scenarios

the two groups are reversed: smart investors borrow and shift their portfolio toward real estate, while illusion agents are deterred from mortgages and housing, by high nominal rates.

The mechanism we emphasize works only if housing serves as collateral. If borrowing was not possible, disagreement about real interest rates would lead some agents to rebalance their portfolios from housing toward bonds and other agents to shift funds in the opposite direction. It is then not obvious why house prices should increase; indeed, in our model, they remain unchanged. However, if agents who perceive low real rates can build leveraged portfolios, thus investing more than their own wealth in housing, disagreement raises the demand for housing sufficiently to generate a boom. Moreover, the effect is stronger the more borrowers can leverage their portfolios: in the model, the equilibrium house price is increasing in the maximal loan-to-value ratio. More generally, broader access to credit and lower transaction costs in the credit market can be expected to work in the same direction.

While our model is motivated by disagreement about real interest rates that emerges because some investors suffer from inflation illusion, our formal analysis only assumes that investors disagree about the real payoff on nominal bonds. The theoretical effect we highlight is thus more general and could apply in situations where disagreement derives from other sources of heterogeneity. One example is differences in tax rates: investors in high tax brackets perceive a lower real return on bonds - and, if interest is tax deductible, a lower cost of borrowing - than investors in lower brackets. Another source of disagreement about real rates is differences in inflation expectations. This is considered in Piazzesi and Schneider (2006), where we use inflation surveys to document differences in expected infla- 
tion rates across age cohorts in the 1970s and quantify the effect of such differences for house and stock price movements at that time.

We have described illusionary investors as investors who mistake changes in nominal interest rates for changes in real rates. This mistake does not require investors to be unaware of inflation or to be wrong about the inflation rate. All that matters is that investors confuse real and nominal returns when making portfolio choice decisions. For example, consider an illusionary investor who compares the utility he obtains from buying a home to the nominal cost of borrowing. This investor agrees with his smart neighbor about expected inflation. However, the difference between the two neighbors is that the smart neighbor actually uses the expected inflation rate to compute the real cost of his mortgage. Indeed, disagreement about real interest rates does not require disagreement about inflationdifferences in agents' understanding of the impact of inflation on returns is enough. ${ }^{2}$

Recently, there has been renewed interest in the empirical implications of inflation illusion in equity and real estate markets. Campbell and Vuolteenaho (2004) decompose the dividend yield on stocks into three components: expected dividend growth, a subjective risk premium (identified from a cross-sectional regression), and a "mispricing term." They show that positive correlation of dividend yields with inflation is mostly due to the mispricing term. This indicates that stocks are undervalued by conventional measures when inflation is high. ${ }^{3}$ Brunnermeier and Julliard (2006) examine the relationship between house prices and inflation. They derive a decomposition for the price-rent ratio, that is, the price-dividend ratio on housing. Using data from the U.K. housing market, they construct a mispricing component of the price-rent ratio that is negatively related to inflation. By their measure, houses thus appear overvalued when inflation is low.

There are few formal models of inflation illusion. The so-called Fed model, widely used by practitioners, is sometimes used to motivate a monotonic relationship between asset prices and inflation. According to the Fed model, inflation illusion leads investors to apply a modified Gordon growth formula to determine the price-dividend ratio on long-lived assets:

2. This observation implies that we cannot derive evidence about illusion or the fraction of illusionary agents in the population from inflation surveys. In particular, many investors may suffer from inflation illusion today, even though the Michigan inflation survey does not indicate much inflation disagreement during the 2000s. It is an open and interesting question how we can design surveys (e.g., about mortgage planning) that are able to distinguish between illusion and disagreement.

3. Cohen, Polk, and Vuolteenaho (2005) study the cross section of stock returns and show that capital asset pricing model (CAPM) betas decrease with the inflation rate. This finding is also consistent with inflation illusion; when inflation is high, the compensation for each unit of market beta is lower than what the overall difference in stock returns and riskless securities would suggest. 
instead of using the real interest rate to discount future (real) cash flows as in the usual formula, investors discount at the nominal rate. The modified formula is useful for thinking about stocks that appear undervalued in the 1970 s and overvalued in the 1990 s. $^{4}$ Its application to the housing market, however, runs into Summers's critique-house prices should be low together with stock prices in the 1970s.

The Fed model does not deliver a complete account of asset prices under inflation illusion because it takes the nominal interest rate as exogenous. It, therefore, sidesteps the question why nominal rates comove with expected inflation. In contrast, our general equilibrium model of inflation illusion determines the nominal rate endogenously and links it to smart investors' inflation expectations. In addition, our model is not subject to the Summers's critique. Indeed, inflation illusion matters in our model when inflation is far from its historical mean in either direction, and it induces a nonmonotonic relationship between mispricing in the housing market and inflation. The inflation illusion hypothesis is thus consistent with housing booms not only in the low-interest 2000s but also in the high-interest 1970s.

Basak and Yan (2005) also consider a general equilibrium model in which preferences of illusion investors are defined over nominal consumption. With power utility, investors who expect high inflation thus effectively discount the future at a lower (higher) rate if the intertemporal elasticity of substitution is larger (smaller) than one and interest rates reflect these preferences. Our approach differs in its emphasis on heterogeneity and housing as collateral (as in Kiyotaki and Moore 1997). Moreover, the preferences of illusion investors in our model do not depend on expected inflation.

The purpose of this chapter is to isolate the effects of inflation illusion on house prices and interest rates in general equilibrium; we thus abstract from many other factors that matter for asset prices. In particular, we do not consider other possible links between inflation and house-price booms. Feldstein (1980) has shown that the tax treatment of houses and mortgages makes housing a more attractive asset when expected inflation is high. On the one hand, inflation increases taxable nominal capital gains, which are more easily sheltered from tax for housing than for, say, equity. On the other hand, the inflation increases tax-deductible nominal mortgage interest and thus lowers the effective cost of borrowing. ${ }^{5}$

The chapter is organized as follows. Section 4.2 presents cross-country

4. Ritter and Warr (2002), Sharpe (2002), and Asness (2003) document that dividend yields on stocks are indeed highly correlated with nominal interest rates.

5. There is an interesting connection between this second effect and our analysis. When smart investors are in different tax brackets, an increase in expected inflation will make the effective costs of borrowing computed by Feldstein more different across households. Agents thus disagree more about (after-tax) real rates when inflation is high. Through the mechanism described in the preceding, this should generate further upward pressure on house prices: agents in high tax brackets would find it cheaper to take out a mortgage and drive up house prices, while agents in low tax brackets would be happy to lend. 
evidence on price-rent ratios, using various house-price measures. Section 4.3 presents our heterogeneous agent model with inflation illusion. Section 4.4 describes equilibrium housing booms in high and low inflation environments. Section 4.5 explains how these equilibria capture the historical experience of the 1970s and 2000s. Section 4.6 concludes and discusses future research. Proofs are collected in the appendix.

\subsection{Cross-Country Evidence}

We construct an annual cross-country data set for the period 1970 to 2004. This sample period is dictated by the availability of house-price data. The data set covers twelve countries: Australia, Canada, France, Germany, Ireland, Italy, Japan, the Netherlands, Spain, Sweden, United Kingdom, and United States.

\subsubsection{Price-Dividend Ratios for Stocks}

To measure the price-dividend ratio for stocks, we rely on MorganStanley Country Indexes available from the Web site www.msci.com. For each country, we obtain two annual series, labeled "price index" (PI) and "gross index" (GI), and compute the dividend yield as $\left(G I_{t} / G_{t-1}\right) /$ $\left(P I_{t} / P I_{t-1}\right)-1$. This procedure recovers a price-dividend ratio with interpretable units. For example, the average PD-ratios in the United States and the United Kingdom were 35.9 and 26, respectively, over the 1970 to 2004 period.

\subsubsection{Price-Rent Ratios for Houses}

The measurement of price-dividend ratios for housing, or price-rent ratios, is more difficult because houses do not trade on exchanges like stocks. We have two options - data from national accounts or data on price indexes constructed by the national central banks available through the Bank of International Settlements (BIS). For the national accounts, we follow the methodology in Piazzesi, Schneider, and Tuzel (2007). We measure the numerator as the value of the aggregate residential housing stock and the denominator as aggregate expenditures on housing services, including owner-estimated rents. We have data from national accounts for the United States and the United Kingdom. Based on price indexes constructed by the national central banks, we measure the national residential price index divided by the consumer price index for each country. These data are available from the BIS. To measure real rents, we use the rent component of each country's consumer price index available from Datastream and divide by the consumer price index. ${ }^{6}$

6. There are two missing observations in the BIS data set. First, we interpolate the 2004 observation for Ireland using data from the Annual Housing Statistics Bulletin published by the 
National account data have several advantages. First, the resulting price-rent ratios have meaningful units because the numerator and denominator are measured in dollars. For example, the average price-rent ratios in the United States and the United Kingdom over the 1970 to 2004 period were 17.6 and 26.5, respectively. In contrast, the units of PD-ratios based on house price and rent indexes are not meaningful; the ratios are normalized to 1 in some base year (which is 1985 in fig. 4.2). The ratios are only useful for looking at percentage changes over time.

Second, the price-rent ratios from national accounts do not involve any quality judgements. Again, the reason is that they are measured in dollars. In contrast, an index construction tracks the evolution of the purchase or rental value of an appropriately defined "unit of housing." The definition of "one unit" of housing does not only involve the square footage of living space but also quality changes of that space over time. The quality judgements are especially problematic for price-rent ratios because the numerator and denominator are constructed by different agencies that may use different definitions.

We can correct for quality changes at low frequencies by taking out linear time trends from real rents in the denominator. We will plot the resulting corrected ratios as dotted lines in our figures. Examples of such low-frequency changes in quality are modern amenities - such as air conditioning, central heating, and electricity — which were absent from homes a century ago. Today's homes also benefit from infrastructure in citiessuch as roads, sidewalks, and public transportation - which has improved slowly over time. However, correcting linear time trends does not take into account high-frequency changes in quality such as quality variations of homes traded over the business cycle or shifting neighborhood effects.

Finally, price-rent ratios from national accounts are available for a long time period, while most house price indexes start in the 1970s. In this chapter, we do not exploit this advantage of the national accounts data, because we focus on stock and house price movements around the high-inflation episode in the 1970s and the recent low-inflation episode.

\subsubsection{Inflation and Real Interest Rates}

For each country, we obtain annual consumer-price inflation and the three-month nominal interest rate on government bonds from the International Monetary Fund's (IMF) International Financial Statistics database. We construct the ex post real rate as the difference between the nominal rate and the inflation rate.

Irish Department of the Environment, Heritage, and Local Government. Second, we interpolate the 1970 observation for Spain, assuming that real house price growth is equal to real rent growth for that year. 


\subsubsection{Cross-Country Empirical Facts}

Figures 4.2 and 4.3 show the price-dividend ratios of houses and stocks together with inflation and the real rate for each country. The PD-ratios of houses in figure 4.2 are measured with BIS data, while those in figure 4.3 are from national accounts. We focus on two episodes. During the inflation episode of the late 1970s and early 1980s, the PD-ratio of housing was relatively high, while the PD-ratio of stocks was relatively low. During the disinflation episode of the 2000s, the same situation emerges. Moreover, ex post real rates were low, or even negative, during both episodes.

\subsection{The Model}

Our model describes heterogeneous households, some of whom may suffer from inflation illusion. Households trade real estate and nominal assets (bonds) with each other as well as a "rest of the economy" sector. Real estate is an asset that cannot be sold short but that can be used as collateral. Bonds are special because they promise nominal payoffs and because they can be held in negative quantities.

\subsubsection{Setup}

There are two dates, 0 and 1, and one consumption good. There is a unit mass of risk-neutral households who discount date 1 consumption by the factor $\beta$. Households can invest in nominal bonds and real estate. A unit of real estate (or "houses") trades at the price $p$ at date 0 and is expected to pay off $p^{\prime}$ at date 1 . This payoff equals the resale price of the house plus any dividend from housing (which may include utility from ownership, etc.) Real estate cannot be sold short. Households can buy or sell one-period nominal bonds. If they choose to borrow by issuing bonds, they must respect a collateral constraint: the value of the bonds issued must be less than $\phi$ times the value of their house. The parameter $\phi$ is the maximal loan-tovalue (LTV) ratio.

Nominal bonds trade at a price $1 / R$ at date 0 , where $R$ is the (gross) nominal interest rate from date 0 to date 1 . Households expect the nominal bond to pay off $x$ goods at date 1. The expected payoff $x$ is subjective and may be different for smart investors and illusionary households. For smart households who understand the Fisher equation and expect inflation $\pi$, the expected payoff of a nominal bond is $x=1 / \pi .^{7}$ Households who suffer

7. To see why, consider a nominal bond that costs $1 / R$ dollars today and pays $\$ 1$ tomorrow, or $1 / q^{\prime}$ units of consumption, where $q^{\prime}$ is the price of consumption tomorrow. Now consider a portfolio of $q$ nominal bonds. The price of the portfolio is $1 / R$ units of numeraire and its payoff is $q / q^{\prime}=1 / \pi$ units of consumption tomorrow. The model thus determines the price $1 /$ $R$ of a nominal bond in $\$$. 

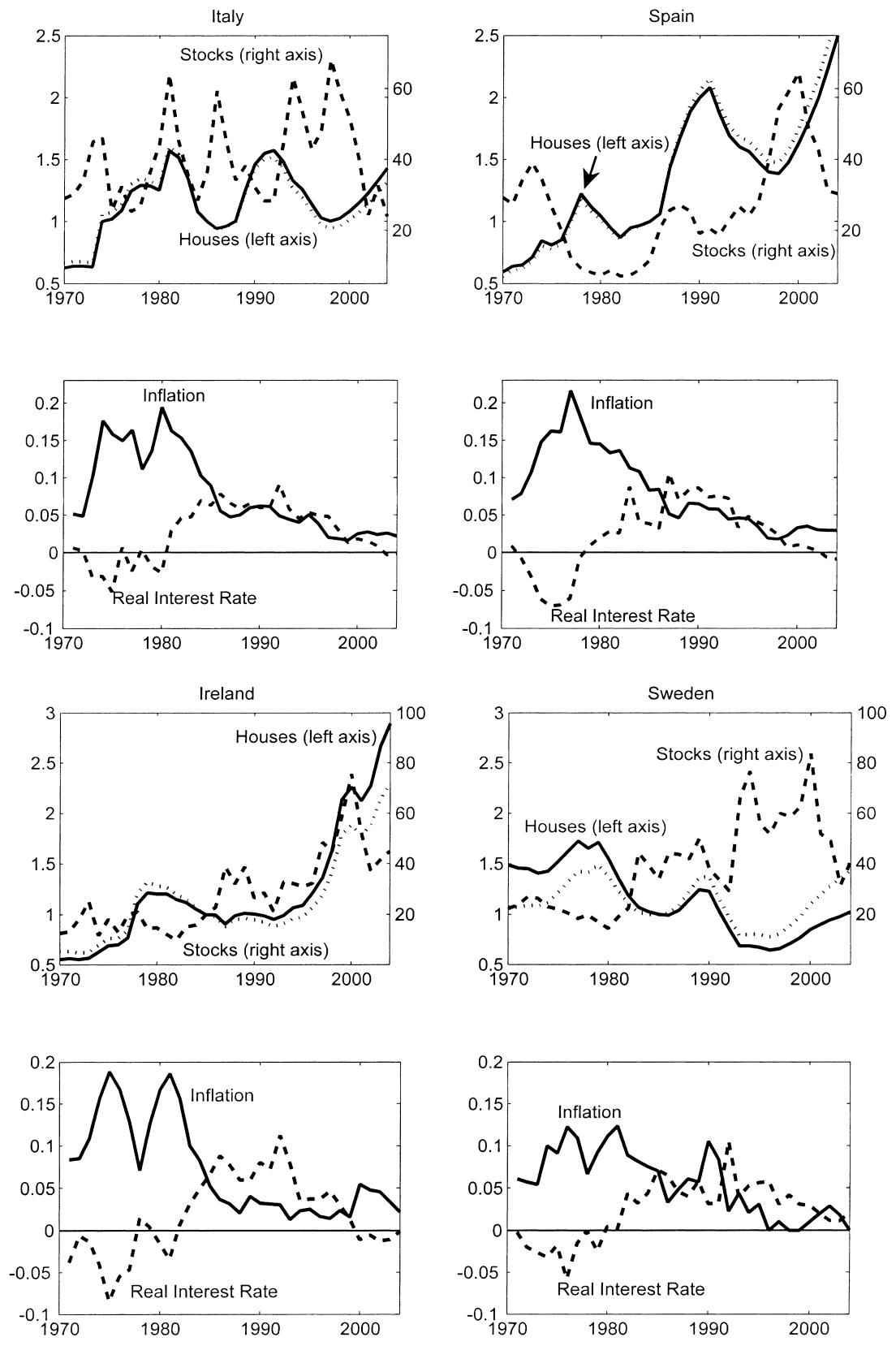

Fig. 4.2 Price-dividend ratios for housing measured with BIS house price indexes (left scale) and stocks (right scale), together with inflation and ex post real rates 

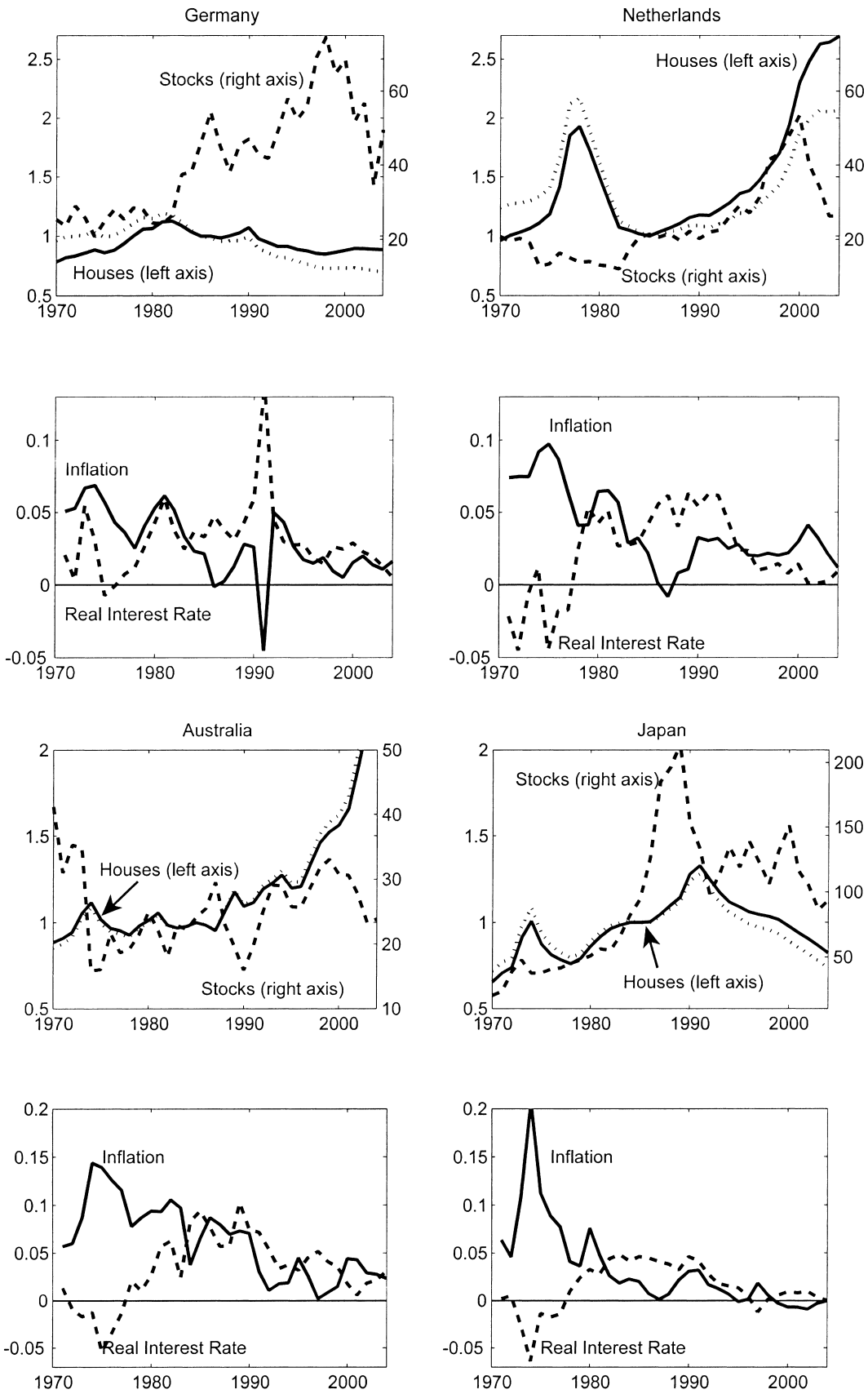

Fig. 4.2 (cont.) Price-dividend ratios for housing measured with BIS house price indexes (left scale) and stocks (right scale), together with inflation and ex post real rates 

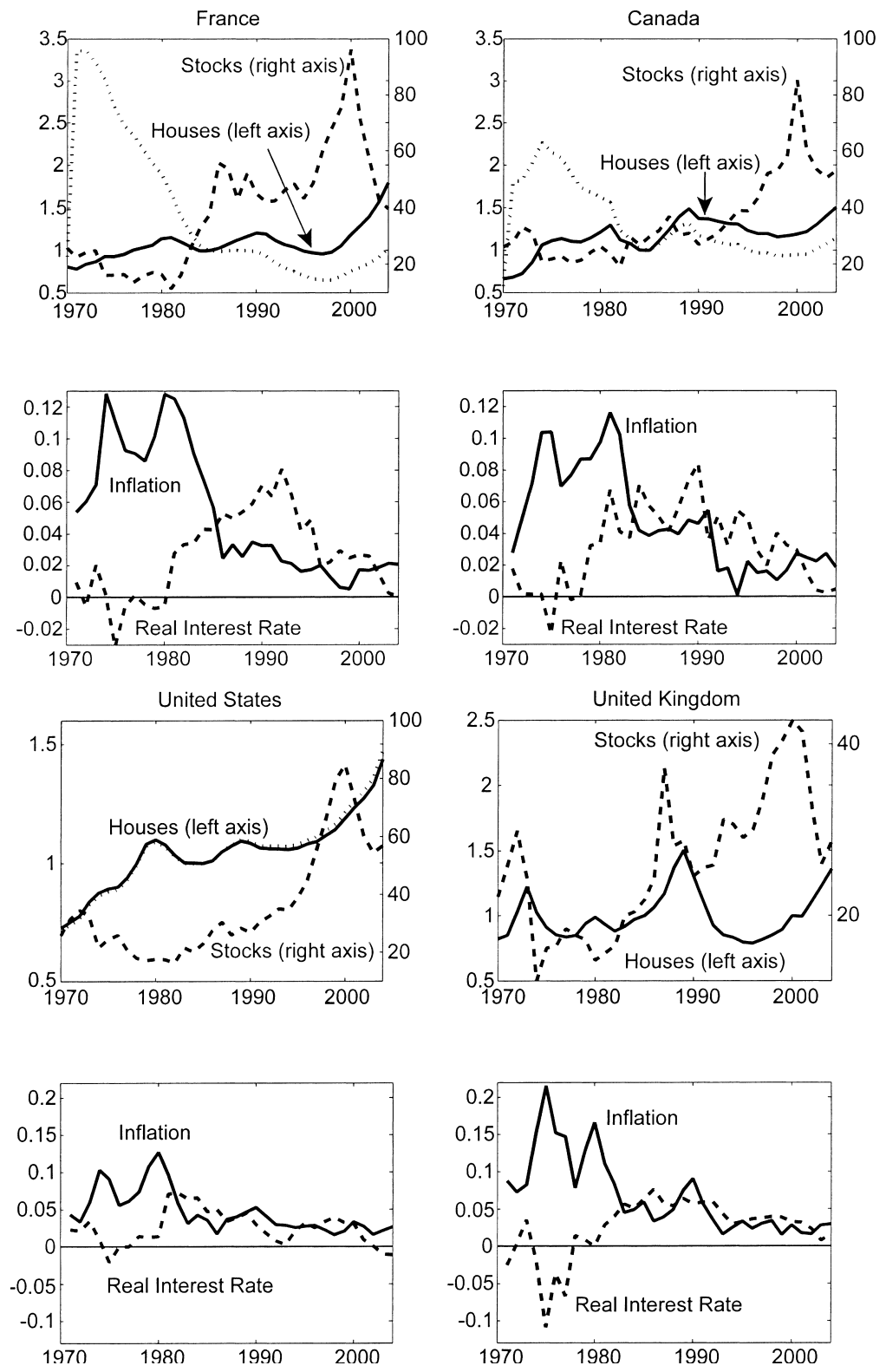

Fig. 4.2 (cont.) 

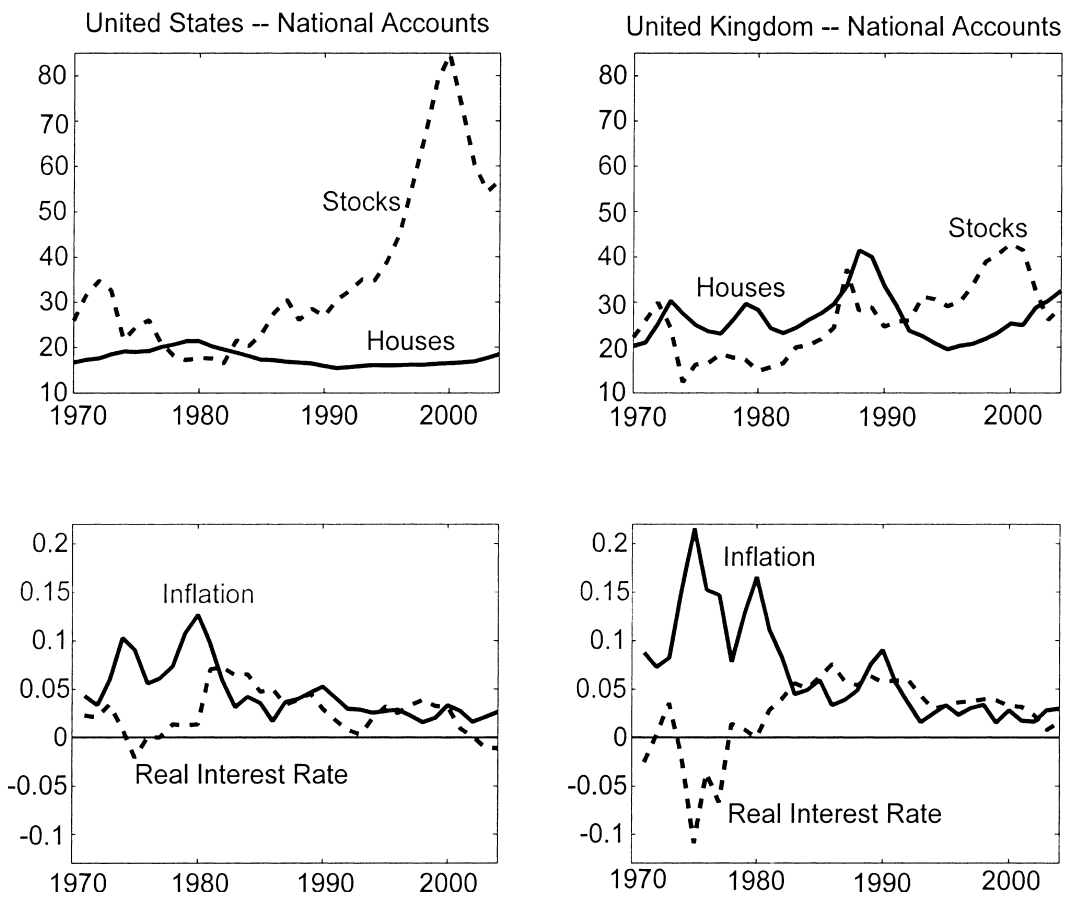

Fig. 4.3 Price-dividend ratios for housing and stocks measured with data from national accounts (on the same scale)

from inflation illusion do not necessarily associate $x$ with their expected inflation rate.

Every household enters the period with an endowment of goods $y$, an endowment of houses $\bar{h}_{0}$, and an amount of goods $\bar{b}_{0}$ from past bond market activity. For given market prices $p$ and $1 / R$, as well as expected payoffs $p^{\prime}$ and $x$, a household chooses consumption $c$ and $c^{\prime}$, the quantity of houses $h$, and the amount of goods invested in bonds $b$ to solve

$$
\begin{gathered}
\max c+\beta c^{\prime} \\
c+b+p h=\bar{w}(p):=\bar{b}_{0}+p \bar{h}_{0}+y \\
c^{\prime}=(R x) b+p^{\prime} h, \\
c, c^{\prime}, h \geq 0, \\
-b \leq \phi p h .
\end{gathered}
$$

This simple setup does not make explicit the utility agents obtain from housing. One way to interpret it is that housing services and other consumption are perfect substitutes, that the dividend from houses owned 
prior to trading at date 0 is contained in $y$, and that the date 1 dividend per unit of house is contained in $p^{\prime}$. Our analysis holds fixed the dividend from housing so that changes in the house price $p^{\prime}$ represent changes in the price-rent ratio. We normalize the aggregate quantity of houses to 1 . The initial endowment of housing units $\bar{h}_{0}$ thus represents the share of the total housing stock that is not acquired by households at date 0 . We assume that households must own all houses after trading at date 0 . In particular, the household sector cannot, on aggregate, sell houses to the rest of the economy. We thus assume $\bar{h}_{0}<1$.

The "rest of the economy" (ROE) sector consolidates the government, foreign, and business sectors. It may also contain "old" households who do not plan for the future because date 0 is the last period of their life. The ROE sells $1-\bar{h}_{0}>0$ units of real estate in the housing market and $\bar{b} \geq 0$ worth of bonds in the credit market. It also redeems all bonds that households enter date 0 with (worth $\bar{b}_{0}$ ). It consumes the proceeds from these trades:

$$
C^{\mathrm{ROE}}=p\left(1-\bar{h}_{0}\right)+\bar{b}-\bar{b}_{0} .
$$

The value of new housing units $p\left(1-\bar{h}_{0}\right)$ corresponds to gross residential investment plus the value of houses sold by "old" households to households planning for the future at date 0 . This interpretation justifies our assumption that $\bar{h}_{0}<1$.

The bond endowment $\bar{b}_{0}$ consists of all payments households receive from past credit market activity, including interest on bonds held in the previous period. Household income $y$ comprises labor income and dividends on real estate the household owns before trading at date 0 . We assume throughout that the sum of this initial nonhousing wealth is large enough that the household sector can afford to buy all bonds supplied by the rest of the economy:

$$
\bar{b}<\bar{b}_{0}+y \text {. }
$$

We view this assumption as mild because changes in aggregate household sector asset positions tend to be small relative to aggregate income, as documented in Piazzesi and Schneider (2006).

We assume that expectations about payoffs on bonds and houses at date 1 are given exogenously. Households agree on the expected payoff from houses $p^{\prime}$. However, the perceived payoff $x$ of a nominal bond depends on households' understanding of real interest rates. To accommodate these differences in perceived bond payoffs, we work with a finite number of household types, indexed by $i$. There are $\alpha_{i}$ households of type $i$, with $\sum_{i} \alpha_{i}=1$. The market prices of bonds and houses at date 0 are determined endogenously: $1 / R$ and $p$, respectively. When choosing portfolios, households thus agree on the expected real housing return $p^{\prime} / p$, but they disagree on the expected real bond return $R x^{i}$, the ex ante real rate. 
We consider temporary equilibria in which date 0 prices are endogenous but expectations about future payoffs are exogenously given (as in Grandmont 1977). A temporary equilibrium consists of a house price $p$ and an interest rate $R$ together with date 0 consumption and asset choices for the various types $\left(c^{i}, b^{i}, h^{i}\right)$ such that (1) households optimize given their (subjective) expected payoffs $\left(p^{\prime}, x^{i}\right)$, and (2) markets for goods and assets clear at date 0 :

$$
\begin{gathered}
1=\sum_{i} \alpha_{i} h^{i}, \\
\bar{b}=\sum_{i} \alpha_{i} b^{i}, \\
\sum_{i} \alpha_{i} c^{i}+C^{\mathrm{ROE}}=y .
\end{gathered}
$$

The market clearing condition for goods illustrates how ROE consumption accommodates deviations of household consumption from household income.

\subsubsection{Modeling Inflation Illusion}

Differences in the subjective bond payoffs $x^{i}$ capture how illusionary and smart investors differ in their perceptions of real rates. We always assume that smart agents expect nominal bonds to pay off $x=1 / \pi$. In other words, smart agents understand the Fisher equation that says that the (ex ante) real interest rate equals the nominal interest rate-quoted in the market - minus the expected inflation rate:

$$
\text { real rate }=\log R-\log \pi .
$$

In contrast, agents who suffer from inflation illusion believe that the payoff of nominal bonds $x$ is constant. As a result, they view real interest rates as equal to nominal interest rates up to a constant:

$$
\text { real rate }=\log R-\text { constant. }
$$

In particular, they interpret positive deviations of the nominal interest rates from its long-run average as an instance of high real rates, and they interpret unusually low nominal rates as unusually low real rates.

To generate time series predictions, we perform comparative statics exercises with respect to the distribution of nominal bond payoffs $x^{i}$. In particular, we compute equilibria for three versions of the model. Our benchmark exercise assumes that all agents agree on the same moderate, expected bond payoff. Intuitively, it captures a time period where expected inflation and the nominal rate are at their long-run averages. While agents in the model act as if they agree, they do think about interest rates in very different terms. Smart agents observe the nominal rate and believe that it reflects moderate inflation because of the Fisher equation (3). In contrast, illusion investors believe that it reflects a normal level of the real rate because of equation (4). 
While this difference in thinking about interest rates does not matter in normal times, it matters when expected inflation and nominal rates deviate from their long-run average. We consider two scenarios where expected bond payoffs differ across agents. Under the 1970s scenario, smart investors expect high inflation and thus believe that bond payoffs are lower than average. However, illusion investors continue to believe that real interest rates are equal to nominal rates up to a constant. Formally, illusion investors thus behave as if bond payoffs are unchanged from the benchmark. Under the 2000s scenarios, smart investors expect low inflation and thus believe that bond payoffs are higher than average. As before, illusion investors act as if bond payoffs have not moved. In both cases, what matters in terms of the model is disagreement about ex ante real rates. It is thus helpful to first analyze a generic case, where some agents expect high bond payoffs and others expect low bond payoffs. This is what we do in the following. We then use the formal results to discuss the 1970s and 2000s scenarios.

\subsection{Equilibrium House Prices and Interest Rates}

In this section, we characterize equilibrium prices, first for a benchmark case with identical subjective real rates and then for the case of heterogeneous subjective real rates. The latter case is used in the following to argue that inflation illusion induces house price booms when smart investors have subjective real rates that are either very high or very low.

\subsubsection{Solution to the Household Problem}

The collateral constraint implies that households cannot borrow against future income. Instead, borrowing is useful only to set up leveraged portfolio strategies that increase the return on wealth. To solve problem (1), a household must, therefore, first determine the best portfolio strategy. If the return on the optimal portfolio is higher than the discount rate $\beta^{-1}$, then it is optimal to invest all date 0 wealth $\bar{w}$. If the best portfolio return is lower than the discount rate, it is instead optimal to save nothing and simply consume $\bar{w}$ at date 0 .

Two polar portfolio strategies are available. If the subjective expected return on bonds, $R x^{i}$, is higher than the return on housing, $p^{\prime} / p$, then the optimal portfolio is 100 percent invested in bonds. If the expected bond return, or equivalently, the expected cost of borrowing, is lower than the housing return, the best portfolio strategy is to borrow up to the collateral constraint and invest in housing. For every unit invested in housing, only $1-\phi$ units must come out of initial wealth because $\phi$ units can be borrowed. Therefore, the expected return on wealth invested in the leveraged portfolio - equivalently, the expected return on housing equity —is

$$
\frac{1}{1-\phi}\left(\frac{p^{\prime}}{p}-\phi R x^{i}\right) \text {. }
$$


In the following, we focus on equilibria in which the return on housing is less than or equal to the discount rate: $p^{\prime} / p \leq \beta^{-1}$. For this case, the optimal consumption-savings and portfolio decisions can be summarized as follows, using two cutoff points for the real rate $R x^{i}$. If $R x^{i}>\beta^{-1}$, the household invests all wealth in bonds; he consumes nothing at date 0 and buys no houses. If $R x^{i}<\phi^{-1}\left[p^{\prime} / p-(1-\phi) \beta^{-1}\right]$, the household borrows up to the collateral constraint, invests his own wealth plus all borrowed funds in housing, and again consumes nothing. Finally, if $R x^{i}$ is in between the two cutoffs (this is possible whenever $p^{\prime} / p<\beta^{-1}$ ), then the household consumes all wealth at date 0 and does not invest. Finally, at the cutoff points themselves, the household is indifferent between neighboring strategies.

\subsubsection{Identical Subjective Real Rates}

As a benchmark, we consider an equilibrium in which all households agree on the same ex ante real rate $R x^{*}$. In this case, the expected bond payoff $x^{*}=1 / \pi^{*}$ is determined by the inflation expectations of smart agents $\pi^{*}$. Because both houses and bonds are in positive net supply, the expected returns on the two assets must be equal and also greater than or equal to the discount rate. We consider an equilibrium in which there is some consumption at date $t$. To make households indifferent between consumption and saving, both returns must equal the discount rate:

$$
R x^{*}=\beta^{-1}=\frac{p^{\prime}}{p} .
$$

Here the first equality is again the Fisher equation: the nominal interest rate equals the ex ante real rate - here the discount rate - multiplied by the expected rate of inflation $\pi^{*}$. The second equality says that the house price is the present discounted value of future payoffs, discounted at the real interest rate. In the benchmark equilibrium, the house price is independent of expected inflation.

We assume that initial endowments and asset supplies are such that markets can clear at these prices. In particular, the supply of assets, with houses evaluated at the prices $p=\beta p^{\prime}$ implied by equation (5), must be smaller than the initial wealth of the household sector:

$$
\bar{b}+\beta p^{\prime}<\bar{b}_{0}+\beta p^{\prime} \bar{h}_{0}+y .
$$

Similarly to equation (2), this assumption is also satisfied if changes in aggregate household asset positions are small relative to income.

\subsubsection{Heterogeneous Subjective Real Rates}

We assume that a fraction $\alpha$ of households expects nominal bonds to have low payoffs $\underline{x}$, while a fraction $1-\alpha$ of households expects high payoffs $\bar{x}>\underline{x}$. We refer to these two groups as low-interest and high-interest 
households, respectively. To again ensure the existence of equilibria in which some consumption takes place at date 0 , we modify equation (6) to

$$
\bar{b}+\beta p^{\prime} \frac{x}{\bar{x}}<\bar{b}_{0}+\beta p^{\prime} \frac{x}{\bar{x}} \bar{h}_{0}+y .
$$

If some new housing units are bought by households planning for the future at date $0\left(\bar{h}_{0}<1\right)$, this condition is stronger than equation (6). In the following equilibria, $\beta p^{\prime(\underline{x} / \bar{x})}$ is an upper bound for the house price. The condition is thus still satisfied provided changes in asset positions-including investment on housing - are small relative to income.

Proposition 1 characterizes equilibrium prices as a function of the share $\alpha$ of low-interest households. We know from the benchmark equilibrium that when households agree on their subjective real rates (that is, $\alpha=0$ or $\alpha=1$ ), the Fisher equation holds and the house price is at its benchmark level $p=\beta p^{\prime}$. When households disagree, the nominal rate reflects a weighted average of their payoff expectations. Moreover, sufficient disagreement in the population generates a house-price boom $\left(p>\beta p^{\prime}\right)$. The proposition formally states this result for the case where the maximal loanto-value ratio $\phi$ is sufficiently large relative to the supply of bonds from the rest of the economy $\bar{b}$. For low $\phi$ or high $\bar{b}$, the same type of equilibrium continues to exist, but it need not be unique. We relegate the analysis of the latter case to the appendix.

Proposition 1: Prices and the Distribution of Views on Ex Ante Real Rates

Suppose $\phi\left(\bar{b}_{0}+y\right)>\bar{h}_{0} \bar{b}$. There is a unique equilibrium in which

(a) the nominal interest rate is continuous and nondecreasing in the fraction $\alpha$ of low-interest agents; there exist cutoffs $\bar{\alpha}_{R}$ and $\underline{\alpha}_{R}$ such that 1 $>\bar{\alpha}_{R} \geq \underline{\alpha}_{R}>0$ and

$$
\begin{array}{ll}
R=\beta^{-1} / \underline{x} & \text { if } \alpha \geq \bar{\alpha}_{R}, \\
R=\beta^{-1} / \bar{x} & \text { if } \alpha \leq \underline{\alpha}_{R}, \\
R \in\left[\beta^{-1} / \bar{x}, \beta^{-1} / \underline{x}\right] & \text { otherwise. }
\end{array}
$$

(b) the house price is hump-shaped in $\alpha$; there exists $\underline{\alpha}_{p} \in\left(0, \underline{\alpha}_{R}\right)$ such that

$$
\begin{array}{ll}
p=\beta p^{\prime} & \text { if } \alpha \notin\left(\underline{\alpha}_{p}, \alpha_{R}\right), \\
p>\beta p^{\prime} & \text { otherwise. }
\end{array}
$$

Proof: See the appendix.

The pattern of interest rates and house prices is shown in figure 4.4. To obtain some intuition, consider first an economy where all agents agree on real interest rates $(\alpha=0)$. This economy is in a benchmark equilibrium, 
Nominal interest rate $\mathrm{R}$

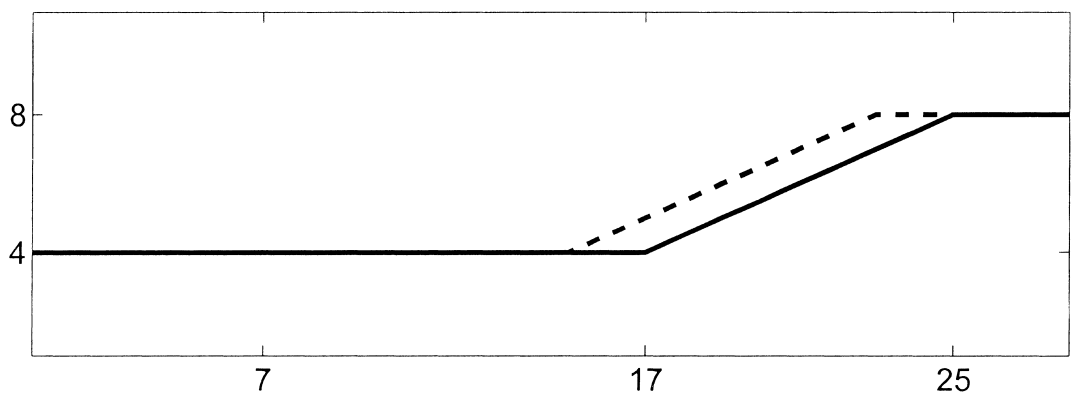

House price $p$

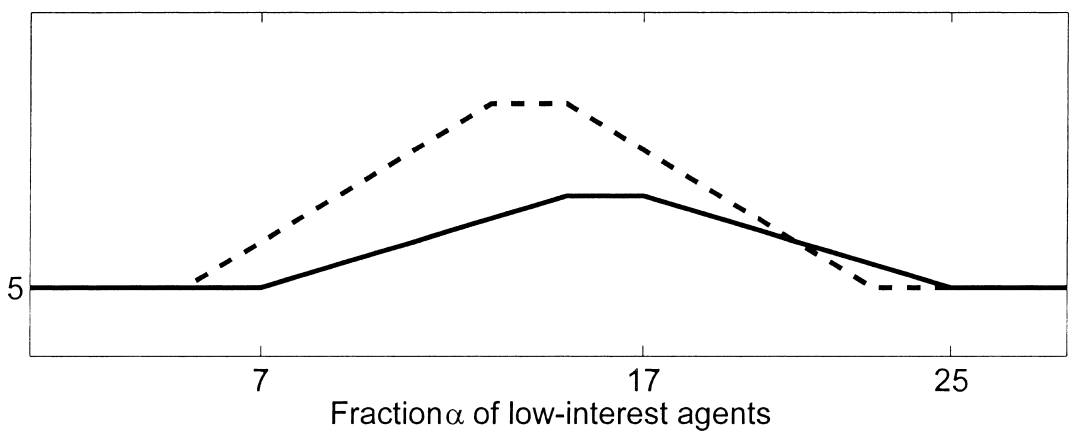

Fig. 4.4 Stylized plot of the equilibrium nominal interest rate $R$ and house price $p$, both as functions of the fraction $\alpha$ of low-interest agents who believe that nominal bonds have low payoffs, $\underline{x}$.

Notes: Solid lines are for an initial equilibrium; dotted lines are for an equilibrium with a higher maximal LTV ratio $\phi$.

where households are indifferent between consumption and savings as well as between different portfolios. Consider now what happens when some high-interest agents are replaced by low-interest agents, that is, $\alpha$ rises. At the original prices, the subjective real interest rate of low-interest agents is below the discount rate and also below the return on housing. Consumption and bonds become unattractive for the low-interest agents: they prefer to invest in housing and also take on mortgages to exploit the low (subjective) cost of borrowing. For small $\alpha$, this makes little difference in the credit market: the high-interest agents, who are indifferent between consumption and bonds, are happy to fund a few more mortgages at the original interest rate. Similarly, the house price need not change as long as there are enough high-interest agents who are willing to sell houses.

The situation changes once there is a critical mass of low-interest agents. As these agents become more numerous, their total wealth - which they invest in housing equity — goes up. Their demand for houses at the original 
benchmark price $\beta p^{\prime}$ eventually outpaces the available supply. For markets to clear, building leveraged portfolios must become less attractive. There are two ways in which this can happen: the cost of borrowing can rise or the return on housing can fall. Part (a) of the proposition shows that the former occurs: the nominal interest rate rises to reflect, at least in part, the low expected bond payoff. Part (b) shows that the house price also reacts: it goes up in order to lower the expected return on housing. Put differently, with sufficient disagreement about ex ante real rates, higher housing demand due to cheap mortgages drives up house prices. This occurs even though everyone agrees that the expected future payoff from houses has not changed.

To see what happens for high $\alpha$, consider an economy where all agents agree on low bond payoffs. This economy is again in a benchmark equilibrium, but now with a high nominal interest rate reflecting the low payoff expectations. Assume next that some low-interest agents are replaced by high-interest agents, that is, $\alpha$ falls. At the original benchmark prices, the subjective real bond return of the high-interest agents now rises above the discount rate and the housing return. High-interest agents thus prefer to invest all wealth in bonds. As long as there are not too many of them, this does not affect prices: they can easily sell houses and buy bonds at the benchmark prices. However, once the high-interest agents reach a critical mass, the nominal interest rate must fall. A lower nominal interest rate not only reduces the bond demand of the high-interest agents, but it also encourages the low-interest agents to take on mortgages, which increases the supply of bonds. The availability of cheap borrowing in turn increases the demand for houses from the low-interest agents: we are back in the region where disagreement increases house prices.

Our finding that disagreement about ex ante real rates leads to houseprice booms is related to the classic result that, in a market with short sale constraints and heterogeneous beliefs, assets are valued by the most optimistic investor (Miller 1977). ${ }^{8}$ The key difference between our setup and Miller's is that we do not assume disagreement about payoffs to the booming asset - in our case, housing — itself. Instead, there is disagreement about subjective real interest rates. The similarity arises because mortgages and housing together can be used to form the composite asset housing equity, defined as housing net of mortgage debt. The collateral constraint implies that housing equity cannot be sold short. Moreover, there is disagreement about its expected payoff $p^{\prime}-b R x$. In equilibrium, the value of housing equity is driven by investors who are most optimistic about its

8. In the simplest version of Miller's argument, risk-neutral investors disagree about stock payoffs. If borrowing is allowed, the stock price must make the most optimistic investor indifferent between holding stocks and bonds - if this were not true, the most optimistic investor would run a leveraged strategy, creating excess demand for stocks. All other investors, who are prevented from shorting the stock, remain on the sidelines. 
payoff, that is, the investors who believe in low real bond payoffs and, hence, a low cost of borrowing.

\subsubsection{The Role of Collateral}

Proposition 2 shows that the possibility of borrowing is critical for our results and that house-price booms driven by disagreement are stronger the higher is the leverage ratio.

\section{Proposition 2: The Role of Collateral}

Suppose $\phi\left(\bar{b}_{0}+y\right)>\bar{h}_{0} \bar{b}$.

(a) If $\phi=0$, the unique equilibrium has $p=\beta p^{\prime}$.

(b) If $\phi>\phi^{*}$, the house price achieves a maximum at

$$
\hat{p}:=\beta p^{\prime}\left(1-\phi+\phi \frac{\bar{x}}{\underline{x}}\right)^{-1} ;
$$

(c) If $\phi>\phi^{*}$, the cutoffs $\underline{\alpha}_{p} \bar{\alpha}_{p}, \bar{\alpha}_{R}$, and $\underline{\alpha}_{R}$ that govern house price and interest rate behavior are decreasing in the maximal LTV value $\phi$. In particular, we have

$$
\begin{aligned}
& \underline{\alpha}_{p}(\phi)=(1-\phi) \beta p^{\prime} / \bar{w}\left(\beta p^{\prime}\right), \\
& \bar{\alpha}_{p}(\phi)=1-\left(\bar{b}+\phi \beta p^{\prime}\right) / \bar{w}\left(\beta p^{\prime}\right) .
\end{aligned}
$$

ProOF: See the appendix.

Part (a) of the proposition says that if the maximal LTV ratio $\phi$ is equal to zero - in other words, bond holdings are constrained to be nonnegative - then the house price is constant regardless of the extent of disagreement. In an economy without borrowing, disagreement about real rates will only be reflected in the portfolio positions: low-interest agents perceive a low return on bonds and hold only houses, while high-interest agents perceive a high return on bonds and hold only bonds. The possibility of leverage is thus necessary for disagreement to generate house-price booms. Part (b) says that when there is sufficient leverage - here we focus again on the case $\phi>\phi^{*}$ that is also considered in Proposition 1 - the maximal price $\hat{p}$ that can occur in a house-price boom is increasing in the loan-to-value ratio $\phi$. The comparative static of increasing $\phi$ is represented by the dotted lines in figure 4.4 .

Part (c) characterizes the cutoff levels for the fraction of low-interest agents in terms of the maximal LTV ratio $\phi$. It says that the cutoffs $\underline{\alpha}_{p}$ and $\bar{\alpha}_{p}$ for the house price are decreasing in the maximal leverage ratio $\phi$ that borrowers can achieve. At values of $\alpha$ in the interval $\left[\underline{\alpha}_{p}, \bar{\alpha}_{p}\right]$, there is sufficient disagreement such that a house-price boom must occur in any equilibrium. Higher $\phi$ means that an individual borrower can issue more bonds relative to his own wealth and can thus invest a larger multiple of his own 
wealth in housing. The effect on prices is best seen by starting from an equilibrium with agreement. Suppose first that everyone agrees on high real rates and replace a few agents with low-interest agents, who now become leverages. Higher demand for houses per individual borrower means that it takes fewer leveragers to upset the original equilibrium and force an increase in the house price. This explains why the lower bound $\underline{\alpha}_{p}$ is decreasing in $\phi$.

For the converse thought experiment, suppose that initially everyone agrees on low real rates and then replace a few agents with high-interest types. At the original equilibrium prices, the high-interest agents invest exclusively in bonds. With higher $\phi$, it takes more bond investors to upset the original equilibrium because low-interest investors can absorb more bond demand simply by issuing more mortgages, even without an increase in the house price. Therefore, it takes more bond investors to force a drop in interest rates that finally leads to an increase in the house price. This explains why the upper bound $\bar{\alpha}_{p}$ is also decreasing in $\phi$. The upper bound is also decreasing in the supply of bonds from the rest of the economy. The more such bonds are outstanding, the less important it is for low-interest investors to supply additional bonds. It thus again takes more high-interest types to force a drop in the interest rate.

\subsection{House-Price Booms and Inflation}

To compare the behavior of house prices across decades, consider now three distinct environments. Let $x^{*}$ denote bond payoff expectations in a normal environment with average inflation and nominal rates. As discussed in the preceding, illusion agents always expect a bond payoff $x^{*}$ and do not relate it to their expected inflation rate. Let $x^{l o}<x^{*}$ denote a low payoff that was expected by smart investors during the 1970s when they expected inflation to be high, $x^{l o}=1 / \pi^{h i}$. Let $x^{h i}=1 / \pi^{l o}>x^{*}$ denote a high bond payoff that was expected by smart investors in the 2000s when they expected low inflation, $\pi^{l o}<\pi^{h i}$. In a normal year, smart investors also expect a payoff equal (or close) to $x^{*}=1 / \pi^{*}$. If the two investor types happen to agree, the economy is simply in a benchmark equilibrium, where the Fisher equation (for the smart investors) implies a nominal interest rate of $\beta^{-1} \pi^{*}$ and the house price is $\beta p^{\prime}$.

Now consider the 1970s scenario, where smart investors' inflation expectations jump to $\pi^{h i}>\pi^{*}$. The price reaction follows from Propositions 1 and 2 , setting $\underline{x}=x^{l o}=1 / \pi^{h i}$ and $\bar{x}=x^{*}$. Suppose that at the relevant parameters $(\alpha, \phi)$, the economy is in the region described in Proposition 2, where the nominal interest rate rises above $\beta^{-1} \pi^{*}$ but not all the way to

9. Even if the agreement is not perfect and the two payoffs are simply close, part (b) of Proposition 1 says that the house price will be close to its benchmark value. 
$\beta^{-1} \pi^{h i}$, while the house price rises above $\beta p^{\prime}$. We then obtain an equilibrium in which a house-price boom coincides with a high nominal interest rate. When smart investors see the nominal rate, they consider borrowing a good deal because the nominal rate does not fully reflect their high inflation expectations. Their demand for collateral drives up house prices. In contrast, illusion agents see the nominal rate and believe times are great for investing in bonds.

Under the 2000s scenario, smart investors' inflation expectations are below the long run average at $\pi^{l o}<\pi^{*}$. We again read off prices from Propositions 1 and 2 , now setting $\bar{x}=x^{h i}=1 / \pi^{l o}$ and $\underline{x}=x^{*}$. If the economy is in the region where interest rates partially adjust, we obtain a house-price boom that goes along with low nominal interest rates. Moreover, the role of the two investor types is now reversed: under the 2000s scenario, it is illusion investors who are eager to borrow as they perceive low real rates. Illusion investors' demand for houses thus drives up house prices. In contrast, smart investors prefer to invest in bonds.

\subsubsection{Structural Change and the Size of House-Price Booms}

Changes in the maximal LTV ratio $\phi$ can be interpreted as the result of financial innovation-for example, in the screening technology available to intermediaries who originate mortgages. Proposition 2 suggests two ways in which financial development is conducive to housing booms in a low-inflation environment, as under the 2000s scenario. First, part (a) of the proposition says that higher leverage directly leads to higher house prices. Second, part (b) says that, with more opportunities for leverage, it takes fewer inflation illusion agents to generate enough disagreement for a house-price boom. ${ }^{10}$ Taken together, these observations suggest that financial development may explain why the house-price booms of the 2000 s were typically stronger than those of the 1970s.

Another consequence of financial development is that the fraction of households who participate in mortgage markets has increased recently, especially among lower income households (see, for example, Doepke and Schneider 2006). The model shows that an extreme increase in the participation rate is conducive to housing booms $(\phi=0$ and $\phi>0$ correspond to a zero and a 100 percent participation rate, respectively). More generally, one would expect that a smaller increase has similar effects. Moreover, an inflow of poor unsophisticated investors might generate more disagreement about real rates.

Another structural change that occurred between the 1970s and the

10. Interestingly, the same argument does not apply to illusion-induced booms in highinflation environments. The discussion after Proposition 2 implies that, in high-inflation environments, higher leverage implies that it takes more illusion investors to generate a boom. 
2000s is the increased opening of U.S. credit markets to foreigners. Doepke and Schneider (2006) show that the net nominal asset position of the U.S.household sector has reached historical lows in recent years, while foreigners have become important net nominal lenders. In our model, this change is captured by a reduction in the supply of bonds $\bar{b}$ provided to the household sector by the rest of the economy. Proposition 2 shows that higher $\bar{b}$ increases the parameter region where housing booms can occur by keeping nominal interest rates low even if a lot of investors believe that real rates are low. Strong foreign demand for bonds thus facilitates housing booms due to illusion in both high- and low-inflation environments.

\subsubsection{The Relationship between Inflation and Real Estate "Mispricing"}

Consider an econometrician whose goal is to decompose house prices into a "fundamental" and a (residual) "mispricing" component. In the typical application, the fundamental component is taken to be a riskadjusted present discounted value of profits to be made from the housing stock. If the data were generated by our (risk-neutral) model, correct measurement of rents and real interest rates would thus lead the econometrician to recover the benchmark price $\beta p^{\prime}$ as the fundamental component. The mispricing is then simply $p-\beta p^{\prime}$, a series with two peaks that occur during the 1970s and 2000s. It follows that the relationship between inflation and real estate mispricing is nonlinear: housing booms that push prices beyond fundamentals occur both at high inflation rates (during the 1970s) and at low inflation rates (during the 2000s).

If data were generated simply by repeatedly running our model with different inflation expectations, an econometrician who regresses his measure of mispricing on inflation should not detect a significant relationship. However, the coefficients in a linear regression could turn out to be (misleadingly) significant if there is another factor that changes over time. As one example, suppose that there is structural change in the credit market, so that $\phi$ increases over time, as discussed in the preceding. In this case, the first peak of the real estate mispricing series during the high 1970s inflation is smaller than its second peak during the low 2000s inflation. Thus, a linear regression of mispricing on inflation might uncover a significantly negative linear relationship between real estate mispricing and inflation. In this example, the omitted variable "credit market development" will be responsible for the finding, although the true relationship between inflation and mispricing is nonlinear.

The relationship between real estate mispricing and inflation is also sensitive to how the fundamental component is measured in the face of structural change. For example, suppose that deregulation of rental markets induces a trend in $\beta p^{\prime}$ - and, hence, house prices - that has nothing to do with inflation. Consider now an econometrician who determines the fun- 
damental value of housing by estimating a stationary process with the same mean as the observed house price over his or her sample. Because he or she ignores the trend in fundamentals, this econometrician will tend to find negative mispricing early in his sample period and positive mispricing later in the sample period. If inflation also happened to decrease over the sample period, there will be a spurious negative relationship between mispricing and inflation that has nothing to do with inflation illusion.

\subsection{Conclusion}

This chapter has considered a stylized economy with heterogeneous agents, some of whom suffer from inflation illusion. Our model predicts a nonmonotonic relationship between house price-rent ratios and inflation: house prices are high whenever inflation is far away from its historical average. According to the model, a high-inflation environment - such as the 1970s - is a time when smart households drive up house prices because they are able to borrow cheaply from illusionary households. The latter do not realize that nominal rates are high only because expected inflation is high and thus perceive higher real rates than smart households. In contrast, in a low-inflation environment — such as the 2000s - the role of the two groups is reversed: illusionary households drive up house prices because they think they are borrowing cheaply from smart households. They do not realize that nominal interest rates are low only because of low expected inflation and thus perceive lower real rates than smart households. Recent financial market development has made borrowing easier, which might explain why the housing boom of the 2000s is more pronounced than the 1970s boom.

We emphasize that general equilibrium effects matter for thinking about the effect of inflation illusion on asset prices. While the Fed model consists of a relationship between endogenous variables, our model jointly determines both the nominal interest rate and house prices. We have shown that investor heterogeneity is one way to reconcile the comovement of nominal rates and inflation with real effects of inflation illusion and also to avoid Summers's critique. An important task for future research is to quantify the implications of inflation illusion and to compare the effect we have derived here to other candidate explanations for house-price booms.

Another interesting issue is the effect of inflation illusion on stock prices. The cross-country evidence in this chapter shows that the price-dividend ratios of housing and stocks often move in opposite directions. The mechanism we emphasize can help produce such negative comovement. Indeed, disagreement about real interest rates makes bonds more attractive to investors who perceive high real rates, while it makes real estate more attractive to investors who perceive low real rates. In relative terms, stocks thus 
become less attractive to both investor types. The resulting shift in portfolio demand away from stocks should thus lower stock prices while increasing house prices.

\section{Appendix}

This appendix characterizes the equilibriums of our model. We begin with three lemmas. Lemma 1 shows that, in any equilibrium, we must have $\beta^{-1} / \bar{x} \leq R \leq \beta^{-1} / \underline{x}$ and $p \geq \beta p^{\prime}$. Lemma 2 derives conditions for the existence of equilibriums with $p=\beta p^{\prime}$, while Lemma 3 does the same for the case $p>\beta p^{\prime}$. Propositions $1^{*}$ and $2^{*}$ then provide a full description of the equilibriums that can occur. In particular, these propositions do not assume that $\phi\left(\bar{b}_{0}+y\right)>\bar{h}_{0} \bar{b}$, an assumption that was made in the text to ensure uniqueness. We provide a brief discussion of why multiplicity can occur-and why it is not particularly interesting from an economic perspective here-after Proposition 2*. Finally, we derive Propositions 1 and 2 stated in the text.

Lemma 1: In any equilibrium, $\beta^{-1} / \bar{x} \leq R \leq \beta^{-1} / \underline{x}$ and $p \geq \beta p^{\prime}$.

PROOF: If $R<\beta^{-1} / \bar{x}$, then no household invests in bonds, which cannot be an equilibrium because bonds are in positive net supply.

If $p<\beta p^{\prime}$, then it is optimal for both household types to save all initial wealth because the real return on housing $p^{\prime} / p$ is higher than the discount rate. Summing up the market clearing conditions for bonds and houses, the house price must satisfy

$$
p+\bar{b}=\bar{b}_{0}+p \bar{h}_{0}+y .
$$

Because $\bar{h}_{0}<1$ and condition (2) holds, the solution for $p$ is positive. But now condition (6) implies that

$$
\frac{p^{\prime}}{p}=\frac{p^{\prime}\left(1-\bar{h}_{0}\right)}{y+\bar{b}_{0}-\bar{b}}<\beta^{-1},
$$

a contradiction.

Finally, if $R>\beta^{-1} \underline{x}$, the real rate on bonds perceived by both types is strictly higher than the discount rate, and, because $p \geq \beta p^{\prime}$ (by the argument in the previous paragraph), the real bond return is also strictly higher than the return on housing. It follows that no agent wants to hold housing, which cannot be an equilibrium because houses are in positive net supply. 
Lemma 2: Define the cutoffs:

$$
\begin{gathered}
\bar{\alpha}_{p}=1-\left(\bar{b}+\phi \beta p^{\prime}\right) / \bar{w}\left(\beta p^{\prime}\right), \\
\underline{\alpha}_{p}=(1-\phi) \beta p^{\prime} / \bar{w}\left(\beta p^{\prime}\right) .
\end{gathered}
$$

An equilibrium with $p=\beta p^{\prime}$ exists if and only if either

(a) $\alpha \geq \bar{\alpha}_{p}$, in which case $R \underline{x}=\beta^{-1}$, or

(b) $\alpha \leq \underline{\alpha}_{p}$, in which case $R \overline{\bar{x}}=\beta^{-1}$.

Proof: We assume first that $R \bar{x}>\beta^{-1}$, which leads to case (a) and in the following consider $R \bar{x}=\beta^{-1}$, which leads to case (b). If $R \bar{x}>\beta^{-1}=p^{\prime} / p$, then high-interest agents hold only bonds. We must have $R \underline{x} \leq \beta^{-1}$ as otherwise nobody holds houses. We cannot have $R \underline{x}<\beta^{-1}$. If this were true, lowinterest agents would want to invest all wealth in a leveraged portfolio strategy. All agents would then invest all wealth so that the value of the total asset supply would equal the total value of wealth, and the house price would be determined by equation (A1). As argued in the proof of Lemma 1 , condition (6) would then imply $p^{\prime} / p<\beta^{-1}$ (cf. equation [A2]), which contradicts our assumption that $p=\beta p^{\prime}$.

We conclude that equilibria with $p=\beta p^{\prime}$ and $R \bar{x}>\beta^{-1}$ must have $R \underline{x}=$ $\beta^{-1}$. Low-interest agents are thus indifferent between bonds, houses, and consumption, while high-interest agents hold only bonds. Markets can clear at these prices as long as there are sufficiently many bonds available to satisfy the demand of the high-interest agents. Bond supply can come either from the ROE sector or because low-interest agents issue mortgages. We obtain the cutoff for case (a):

$$
\bar{b}+\phi \beta p^{\prime} \geq(1-\alpha)\left(\beta p^{\prime} \bar{h}_{0}+\bar{b}_{0}+y\right) .
$$

As long as this inequality holds, condition (6) guarantees that the remaining wealth (owned by the low-interest agents) is high enough such that the latter agents can afford to purchase the whole housing stock, that is,

$$
(1-\phi) \beta p^{\prime}<\alpha\left(\beta p^{\prime} \bar{h}_{0}+\bar{b}_{0}+y\right) \text {. }
$$

Because low-interest agents are indifferent between all portfolio strategies, a suitable number of them can be assigned to both markets to ensure market clearing. It follows that equilibriums with $p=\beta p^{\prime}$ and $R \bar{x}>\beta^{-1}$ exist if and only if condition (A3) holds.

Suppose now that $R \bar{x}=\beta^{-1}$. Because $R \underline{x}<\beta^{-1}=p^{\prime} / p$, low-interest agents will use the leveraged strategy and hold no bonds. For an equilibrium of this type to exist, we need the value of the housing stock to be large enough to satisfy the demand of the low-interest agents, which defines the cutoff for case (b):

$$
(1-\phi) \beta p^{\prime} \geq \alpha\left(\beta p^{\prime} \bar{h}_{0}+\bar{b}_{0}+y\right)
$$


If this inequality is satisfied, condition (6) again ensures that the remaining wealth (owned by the high-interest agents) is large enough that the highinterest agents can absorb all bonds issued by the ROE and the low-interest agents, that is,

$$
\bar{b}+\phi \beta p^{\prime}<(1-\alpha)\left(\beta p^{\prime} \bar{h}_{0}+\bar{b}_{0}+y\right) .
$$

It follows that equilibria with $p=\beta p^{\prime}$ and $R \bar{x}=\beta^{-1}$ exist if and only if condition (A4) holds.

Lemma 3: An equilibrium with $p>\beta p^{\prime}$ exists only if $\phi>0$ and at least one of four sets of conditions holds:

(a) $\phi>\bar{h}_{0} \bar{b} /\left(\bar{b}_{0}+y\right):=\phi^{*}$ and

$$
\bar{\alpha}_{p}>\alpha>1-(\bar{b}+\phi \hat{p}) / \bar{w}(\hat{p})
$$

(b) $\phi<\phi^{*}$ and

$$
\bar{\alpha}_{p}<\alpha<1-(\bar{b}+\phi \hat{p}) / \bar{w}(\hat{p}),
$$

(c) $\underline{\alpha}_{p}<\alpha<(1-\phi) \hat{p} / w(\hat{p})$,

(d) $\phi>0$ and $(1-\phi) \hat{p} / \bar{w}(\hat{p}) \leq \alpha \leq 1-(\bar{b}+\phi \hat{p}) / \bar{w}(\hat{p})$.

For all cases, there exist values of $\alpha$ that satisfy the conditions.

Conversely, assume $\phi>0$. If cases (a) or (b) apply, the equilibrium house price and interest rate are given by

$$
\begin{gathered}
p=\frac{(1-\alpha)\left(\bar{b}_{0}+y\right)-\bar{b}}{\phi-(1-\alpha) \bar{h}_{0}}, \\
R=\beta^{-1} \frac{1}{\phi \underline{x}}\left(\frac{\beta p^{\prime}\left[\phi-\bar{h}_{0}(1-\alpha)\right]}{(1-\alpha)\left(y+\bar{b}_{0}\right)-\bar{b}}-(1-\phi)\right) .
\end{gathered}
$$

In case (a), $p$ is decreasing in $\alpha$ and $R$ is increasing in $\alpha$.

If case (c) applies, then $R \bar{x}=\beta^{-1}$ and

$$
p=\frac{\alpha\left(\bar{b}_{0}+y\right)}{1-\phi-\alpha \bar{h}_{0}},
$$

and the price $p$ is increasing in $\alpha$.

If case (d) applies, $p=\hat{p}$ and $R \bar{x}=\beta^{-1}$.

Proof: If $p^{\prime} / p<\beta^{-1}$, high-interest agents do not own houses in equilibrium. Indeed, we know from Lemma 1 that we must have $R \bar{x} \geq \beta^{-1}$. Because $p^{\prime} / p<\beta^{-1} \leq R \bar{x}$, owning houses without leverage is worse than owning bonds for high-interest agents. More generally, even the return on a maximally leveraged strategy is strictly worse than the return on bonds for the high-interest agents: 


$$
\frac{1}{1-\phi}\left(\frac{p^{\prime}}{p}-\phi R \bar{x}\right) \leq \frac{1}{1-\phi}\left(\frac{p^{\prime}}{p}-\phi \beta^{-1}\right)<\beta^{-1} \leq R \bar{x}
$$

Because high-interest agents do not own houses, low-interest agents must be willing to do so, which requires

$$
\frac{1}{1-\phi}\left(\frac{p^{\prime}}{p}-\phi R x\right) \geq \beta^{-1} \text {. }
$$

It follows that we cannot have $\phi=0$, as otherwise $p^{\prime} / p=\beta^{-1}$. To derive the other conditions, we first consider $R \bar{x}>\beta^{-1}$, which corresponds to cases (a) and (b). We then consider $R \bar{x}=\beta^{-1}$, which corresponds to cases (c) and (d).

Cases (a) and (b). We first show that if there is an equilibrium with $p>\beta p^{\prime}$ and $R \bar{x}>\beta^{-1}$, either case (a) or case (b) applies. If $R \bar{x}>\beta^{-1}$, high-interest agents invest all their wealth in bonds and hold no houses. We must then have equation (A8) hold with equality. Indeed, if equation (A8) were to hold strictly, then low-interest agents would invest all wealth in leveraged portfolios so that all agents would save all wealth and the house price would be pinned down by equation (A1). Substituting this price formula back into equation (A8), we obtain

$$
\bar{b}+\tilde{p}>\tilde{p} \bar{h}_{0}+y+\bar{b}_{0},
$$

where $\tilde{p}=\beta p^{\prime}(1-\phi+\phi \beta R \underline{x})^{-1}$. The last inequality contradicts our assumption (7). To see this, define the function

$$
h(p):=\frac{\bar{b}+p}{p \bar{h}_{0}+y+\bar{b}_{0}},
$$

which is strictly increasing because $\bar{h}_{0}<1$ and $\bar{b}<\bar{b}_{0}+y$. We can write equation (A9) as $h(\tilde{p})>1$ and equation (7) as $h\left(\beta p^{\prime} \bar{x} / \underline{x}\right)<1$ so that we would need $\tilde{p}>\beta p^{\prime} \bar{x} / \underline{x}$. However, $R \bar{x}>\beta^{-1}$ implies $\tilde{p}<\overline{\hat{p}}<\beta p^{\prime} \bar{x} / \underline{x}$, a contradiction.

Because (A8) holds with equality, low-interest agents must be indifferent between consumption and holding leveraged portfolios. There must be a subset of low-interest agents that holds all houses and issues $\phi p$ mortgages. These mortgages, together with the debt issued by the ROE, must in turn be held by high-interest agents. Because high-interest agents invest all wealth in bonds, the total outstanding debt must be equal to high-interest agents' wealth. For the bond market to clear, the equilibrium house price must satisfy

$$
\bar{b}+\phi p=(1-\alpha)\left(p \bar{h}_{0}+\bar{b}_{0}+y\right) .
$$

The solution for the house price is equation (A5). The interest rate $R$ is then pinned down by equation (A8), which we have assumed to hold with equality. The solution for the interest rate is equation (A6). 
The solutions $(p, R)$ in equations (A5) to (A6) must satisfy $p>\beta p^{\prime}$ and $R \bar{x}>\beta^{-1}$. Since they are equilibrium prices, they must also be positive, which gives rise to two possibilities. Assume first that

$$
\phi / \bar{h}_{0}>(1-\alpha)>\frac{\bar{b}}{\bar{b}_{0}+y} .
$$

The conditions $p>\beta p^{\prime}$ and $R \bar{x}>\beta^{-1}$ can now be written as

$$
\begin{gathered}
\bar{b}+\phi \beta p^{\prime}<(1-\alpha)\left(\beta p^{\prime} \bar{h}_{0}+\bar{b}_{0}+y\right), \\
\bar{b}+\hat{p} \phi>(1-\alpha)\left(\hat{p} \bar{h}_{0}+\bar{b}_{0}+y\right),
\end{gathered}
$$

which defines the cutoffs for $\alpha$ in case (a).

A second set of parameters that leads to positive prices is

$$
\bar{b} /\left(\bar{b}_{0}+y\right)>(1-\alpha)>\phi / \bar{h}_{0} .
$$

The conditions $p>\beta p^{\prime}$ and $R \bar{x}>\beta^{-1}$ now define the cutoffs for $\alpha$ in case (b):

$$
\begin{gathered}
\bar{b}+\phi \beta p^{\prime}>(1-\alpha)\left(\beta p^{\prime} \bar{h}_{0}+\bar{b}_{0}+y\right), \\
\bar{b}+\hat{p} \phi<(1-\alpha)\left(\hat{p} \bar{h}_{0}+\bar{b}_{0}+y\right) .
\end{gathered}
$$

It remains to define

$$
\phi^{*}=\bar{h}_{0} \frac{\bar{b}}{\bar{b}_{0}+y} .
$$

We have thus shown that existence of an equilibrium with $p>\beta p^{\prime}$ and $R \bar{x}>\beta^{-1}$ implies either (a) or (b).

We now show that there exist values of $\alpha$ that satisfy these conditions. Begin with case (a), and consider the function

$$
f(p):=\frac{\bar{b}+\phi p}{p \bar{h}_{0}+\bar{b}_{0}+y},
$$

which is continuously differentiable with

$$
f^{\prime}(p)=\frac{\phi\left(\bar{b}_{0}+y\right)-\overline{b h}_{0}}{\left(p \bar{h}_{0}+\bar{b}_{0}+y\right)^{2}},
$$

and is, therefore, strictly increasing if and only if $\phi>\phi^{*}$. Conditions (A12) and (A13) can be written as $f(\hat{p})>1-\alpha>f(\beta p)$. If follows that, if $\phi>\phi^{*}$, there exist values of $\alpha$ that satisfy both conditions simultaneously. Any such value of $\alpha$ will also satisfy equation (A11) because

$$
\lim _{p \rightarrow \infty} f(p)=\phi / \bar{h}_{0}>f(\hat{p})>1-\alpha>f\left(\beta p^{\prime}\right)>f(0)=\frac{\bar{b}}{\bar{b}_{0}+y} .
$$

A similar argument applies to case (b). Indeed, equations (A15) and (A16) can be written as $f(\hat{p})<1-\alpha<f(\beta p)$. If $\phi<\phi^{*}$, then $f$ is strictly decreas- 
ing, which implies that there are values of $\alpha$ that satisfy equations to (A14) to (A16).

Suppose now that we have a pair $(\phi, \alpha)$ that satisfies the conditions of case (a) or (b), and suppose prices are given by equations (A5) and (A6). The bond market clears by construction of the house price. For the housing market to clear, the wealth of the low-interest agents evaluated at $p$ must be high enough that these agents can afford to hold all houses:

$$
(1-\phi) p<\alpha\left(p \bar{h}_{0}+\bar{b}_{0}+y\right) \text {. }
$$

Because equation (A10) is assumed to hold, equation (A17) is equivalent to

$$
\bar{b}+p \leq p \bar{h}_{0}+\bar{b}_{0}+y \text {. }
$$

But this inequality is implied by equation (7) because $R \bar{x}>\beta^{-1}$ guarantees $p<\hat{p}$. If we are in case (a), equation (A11) holds and implies that the price (A-5) decreasing in $\alpha$, while the interest rate (A6) is increasing in $\alpha$.

To sum up, we have shown that an equilibrium with $p>\beta p^{\prime}$ exists if either $\phi>\phi^{*}$ and conditions (A12) and (A13) hold or $\phi<\phi^{*}$ and conditions (A15) and (A16) hold. For either case, there are values of $\alpha$ that satisfy the conditions. Finally, if either pair of conditions holds, there is an equilibrium with prices (A5) and (A6) that satisfies $p>\beta p^{\prime}$.

Case (c). We show that if there is an equilibrium such that $p>\beta p^{\prime}, R \bar{x}=$ $\beta^{-1}$ and equation (A8) holds with strict inequality, then case (c) applies. Under these conditions, low-interest agents invest all their wealth in a leveraged portfolio strategy. Because high-interest agents do not hold houses, housing equity in the entire housing stock must equal the wealth of lowinterest agents:

$$
(1-\phi) p=\alpha\left(p \bar{h}_{0}+\bar{b}_{0}+y\right) .
$$

The solution for the house price is equation (A7).

The solution for $p$ must be positive so that $\alpha \leq(1-\phi) / \bar{h}_{0}$. In addition, it must satisfy $p>\beta p^{\prime}$ as well as equation (A8) with strict inequality. This implies the cutoffs for case (c):

$$
\begin{gathered}
(1-\phi) \beta p^{\prime}<\alpha\left(\beta p^{\prime} \bar{h}_{0}+\bar{b}_{0}+y\right), \\
(1-\phi) \hat{p}>\alpha\left(\hat{p} \bar{h}_{0}+\bar{b}_{0}+y\right) .
\end{gathered}
$$

We now show that there exist values of $\alpha$ that satisfy the conditions of case (c). The function

$$
g(p):=\frac{(1-\phi) p}{p \bar{h}_{0}+\bar{b}_{0}+y}
$$

is strictly increasing and continuous in $p$, with $\lim _{p \rightarrow \infty} g(p)=(1-\phi) / \bar{h}_{0}$. It follows that there exist values of $\alpha$ that satisfy $g\left(\beta p^{\prime}\right)<\alpha<g(\hat{p})$, which is equivalent to equations (A19) and (A20). 
Finally, suppose that there is an $\alpha$ such that equations (A19) and (A20) hold and that the house price is given by equation (A7). This price is positive because $g$ is strictly increasing so that equation (A21) implies

$$
\alpha<g(\hat{p})<\lim _{p \rightarrow \infty} g(p)=(1-\phi) / \bar{h}_{0} .
$$

The house market clears by construction. For the bond market to clear, the wealth of the high-interest agents must be high enough at $p$ to absorb all bonds, that is,

$$
\bar{b}+\phi p<(1-\alpha)\left(p \bar{h}_{0}+\bar{b}_{0}+y\right) .
$$

Because equation (A18) holds, equation (A21) is equivalent to

$$
\bar{b}+p<p \bar{h}_{0}+\bar{b}_{0}+y .
$$

This inequality is implied by equation (7) because equation (A8) guarantees $p<\hat{p}$. We have thus shown that an equilibrium with $p>\beta p^{\prime}$ and $R \bar{x}=\beta^{-1}$ exists only if equations (A19) and (A20) hold. There are values of $\alpha$ that satisfy these conditions. Given the conditions, there is an equilibrium with $R \bar{x}=\beta^{-1}$ and house price (A7). The house price is also increasing in $\alpha$.

Case (d). We show that if there is an equilibrium such that $p>\beta p^{\prime}, R \bar{x}=$ $\beta^{-1}$ and equation (A8) holds with equality, then case (d) applies. Substituting $R \bar{x}=\beta^{-1}$ into equation (A8) and solving for the house price, we obtain $p=\hat{p}$. Because $R \bar{x}=\beta^{-1}>p^{\prime} / p$, high-interest agents do not hold houses. Because $R \underline{x}<\beta^{-1}$, low-interest agents do not hold bonds. For the house market to clear, the wealth of the low-interest agents-evaluated at the price $\hat{p}$ - must be high enough so that these agents can afford the housing equity required to purchase the entire housing stock:

$$
(1-\phi) \hat{p} \leq \alpha\left(\hat{p} \bar{h}_{0}+\bar{b}_{0}+y\right) .
$$

At the same time, bond market clearing requires that the wealth of the high-interest agents is high enough so that they can absorb all bonds:

$$
\bar{b}+\phi \hat{p} \leq(1-\alpha)\left(\hat{p} \bar{h}_{0}+\bar{b}_{0}+y\right) .
$$

We have thus derived the conditions for case (d). Condition (7) implies that there exist values of $\alpha$ that satisfy both inequalities. Finally, if there is an $\alpha$ that falls under case (d), then equation (A22) says that we can pick a subset of the low-interest agents that holds all houses as part of leveraged portfolios, while equation (A23) says that we can pick a subset of the highinterest agents who hold all bonds.

Proposition 1*:

(a) For every maximal LTV ratio $\phi<1$, there exist cutoffs $\bar{\alpha}_{R}$ and $\underline{\alpha}_{R}$ such that $1>\bar{\alpha}_{R} \geq \alpha_{R}>0$, and the equilibrium nominal interest rate satisfies 


$$
\begin{array}{ll}
R=\beta^{-1} / \underline{x} & \text { if } \alpha \geq \bar{\alpha}_{R}, \\
R=\beta^{-1} / \bar{x} & \text { if } \alpha \leq \underline{\alpha}_{R}, \\
R \in\left[\beta^{-1} / \bar{x}, \beta^{-1} / \underline{x}\right] & \text { otherwise. }
\end{array}
$$

(b) For every maximal LTV ratio $\phi \in(0,1)$, there exist cutoffs $\bar{\alpha}_{p}$ and $\underline{\alpha}_{p}$ such that $\bar{\alpha}_{R} \geq \bar{\alpha}_{p}>\underline{\alpha}_{p}>0$, and the equilibrium house price satisfies

$$
\begin{array}{ll}
p=\beta p^{\prime} & \text { if } \alpha \notin\left(\underline{\alpha}_{p}, \bar{\alpha}_{R}\right], \\
p>\beta p^{\prime} & \text { if } \alpha \in\left(\underline{\alpha}_{p}, \bar{\alpha}_{p}\right), \\
p \in\left[\beta p^{\prime}, \hat{p}\right] & \text { otherwise. }
\end{array}
$$

Moreover, there exists $\alpha \in\left(\underline{\alpha}_{p}, \alpha_{R}\right)$ such that there is an equilibrium with $p=\hat{p}$.

Proof: We first define the cutoffs:

$$
\begin{aligned}
& \bar{\alpha}_{R}= \begin{cases}1-(\bar{b}+\phi \hat{p}) / \bar{w}(\hat{p}) & \text { if } \phi<\phi^{*}, \\
\bar{\alpha}_{p} & \text { if } \phi \geq \phi^{*} .\end{cases} \\
& \underline{\alpha}_{R}= \begin{cases}\bar{\alpha}_{p} & \text { if } \phi<\phi^{*}, \\
1-(\bar{b}+\phi \hat{p}) / \bar{w}(\hat{p}) & \text { if } \phi \geq \phi^{*} .\end{cases}
\end{aligned}
$$

Part (a). If $\phi \geq \phi^{*}$, then there is an equilibrium with $R x=\beta^{-1}$, by case (a) of Lemma 2. Lemmas 2 and 3 imply also that there cannot be any other type of equilibrium. If $\phi<\phi^{*}$, then case (b) of Lemma 3 says that

$$
\bar{\alpha}_{R}=1-(\bar{b}+\phi \hat{p}) / \bar{w}(\hat{p})>1-\left(b+\phi \beta p^{\prime}\right) / \bar{w}\left(\beta p^{\prime}\right) .
$$

This means that for every $\alpha \geq \bar{\alpha}_{R}$, there is an equilibrium with $R \underline{x}=\beta^{-1}$, again by case (a) of Lemma 2. Inspection of the other case in Lemmas 2 and 3 again shows that this is the only equilibrium. Any $\alpha \leq \underline{\alpha}_{R}$ must satisfy the conditions of either case (b) of Lemma 2, or case (c) or case (d) of Lemma 3. It cannot satisfy the conditions of any other case. In all the relevant cases, the equilibrium interest rate is $R \bar{x}=\beta^{-1}$.

Part (b). For $\alpha>\bar{\alpha}_{R}$, the only equilibrium is that of case (a) of Lemma 2, which has $p=\beta p^{\prime}$. If $\alpha \leq \underline{\alpha}_{p}$, the only type of equilibrium is case (b) of Lemma 2, which has $p=\beta p^{\prime}$. If $\underline{\alpha}_{p} \leq \alpha \leq \bar{\alpha}_{p}$, then Lemma 2 does not apply. Comparing the cutoffs, one of the cases in Lemma 3 always applies so that $p>\beta p^{\prime}$. Finally, for every $\phi>0$, there exist values of $\alpha$ such that part (d) of Lemma 3 applies. In the latter equilibrium, $p=\hat{p}$.

Proposition 2*:

(a) If borrowing is not possible $(\phi=0)$, then $p=\beta p^{\prime}$ for all $\alpha$.

(b) The cutoffs $\underline{\alpha}_{p} \bar{\alpha}_{p}, \bar{\alpha}_{R}$, and $\alpha_{R}$ that govern house price and interest rate behavior are decreasing in the maximal LTV value $\phi$. In particular, we have 


$$
\begin{gathered}
\underline{\alpha}_{p}(\phi)=(1-\phi) \beta p^{\prime} / \bar{w}\left(\beta p^{\prime}\right), \\
\bar{\alpha}_{p}(\phi)=1-\left(\bar{b}+\phi \beta p^{\prime}\right) / \bar{w}\left(\beta p^{\prime}\right) .
\end{gathered}
$$

(c) There is a threshold for the maximal LTV ratio $\phi^{*}:=\bar{h}_{0} \bar{b} /\left(\bar{b}_{0}+y\right) \in$ $(0,1)$ such that

(i) if $\phi \in\left(\phi^{*}, 1\right)$, equilibrium is unique for all $\alpha$ and

$$
\bar{\alpha}_{p}(\phi)=\bar{\alpha}_{R}(\phi)>\underline{\alpha}_{R}(\phi)>\underline{\alpha}_{p}(\phi) .
$$

The interest rate is continuous and nondecreasing in the fraction $\alpha$, whereas the house price is continuous and hump-shaped in $\alpha$, with a maximum of $p=\hat{p}$.

(ii) if $\phi \in\left(0, \phi^{*}\right)$, then

$$
\bar{\alpha}_{R}(\phi)>\bar{\alpha}_{p}(\phi)=\underline{\alpha}_{R}(\phi)>\underline{\alpha}_{p}(\phi) .
$$

For $\alpha \leq \bar{\alpha}_{p}(\phi)$, the interest rate and house price are continuous and nondecreasing in the fraction $\alpha$. If $\alpha \geq \bar{\alpha}_{R}(\phi)$, then $R \underline{x}=\beta^{-1}$ and $p=\beta p^{\prime}$. If $\alpha \in\left[\bar{\alpha}_{p}(\phi), \bar{\alpha}_{R}(\phi)\right]$, there can be up to three equilibriums with $R \in\left[\beta^{-1} / \bar{x}\right.$, $\left.\beta^{-1} / \underline{x}\right]$ and $p \in\left[\beta p^{\prime}, \hat{p}\right]$.

PROOF: Part (a). If $\phi=0$, then Lemma 3 does not apply. The result follows directly from Lemma 2.

Part (b). The formulas for $\bar{\alpha}_{p}$ and $\underline{\alpha}_{p}$ follow directly from the proof of Proposition 1. These cutoffs are decreasing in $\phi$ because $\bar{w}$ is positive and does not depend on $\phi$. To show that $\bar{\alpha}_{p}$ and $\underline{\alpha}_{p}$ are also decreasing in $\phi$, it is sufficient to show that $(b+\phi \hat{p}) / \bar{w}(\hat{p})$ is increasing in $\phi$. The derivative

$$
\frac{d[(b+\phi \hat{p}) / \bar{w}(\hat{p})]}{d \phi}=\frac{\hat{p}}{\bar{w}(\hat{p})^{2}} \frac{\bar{w}(\hat{p})-[1-(\underline{x} / \bar{x})] \bar{h}(\bar{b}+\hat{p} \phi)}{1-\phi+\phi(\underline{x} / \bar{x})}
$$

is positive because equation (7) guarantees $\bar{w}(\hat{p})>\bar{b}+\hat{p}$ and $h_{0}, \phi$ and $\underline{x} / \bar{x}$ are all smaller than one.

Part (c). Our assumption equation (2) can be written as

$$
\bar{w}\left(\beta p^{\prime}\right)>\bar{b}+\beta p^{\prime} \phi,
$$

and, therefore, implies that $\bar{\alpha}_{p}>\underline{\alpha}_{p}$ for all $\phi$. Case (c) of Lemma 3 implies that $\underline{\alpha}_{R}>\underline{\alpha}_{p}$ for all $\phi$.

If $\phi>\phi^{*}$, the conditions of Lemmas 2 and 3 are mutually exclusive, and exactly one case of Lemma 3 can be relevant for a given value of $\alpha$. Equilibrium is thus unique. Moreover, Lemma 3 implies that the price is increasing in $\alpha$ in case (c) and decreasing in case (a). Comparing the price formulas shows that the price is continuous and hump-shaped. Similarly, case (a) of Lemma 3 says that the interest rate is increasing, while it is constant in all other cases. Comparison of the formulas shows that the interest rate is also continuous. 
If $\phi<\phi^{*}, \bar{\alpha}_{R}>\bar{\alpha}_{p}$ follows from case (b) of Lemma 3. Unless $\alpha \in\left[\bar{\alpha}_{p}, \bar{\alpha}_{R}\right]$, exactly one of the cases in Lemma 3 applies so that equilibrium is unique. If $\alpha \in\left[\bar{\alpha}_{p}, \bar{\alpha}_{R}\right]$, then case (a) of Lemma 2 as well as cases (b) and (c) of Lemma 3 can in principle all apply. Therefore, there can be up to three equilibriums.

\section{Remarks}

If $\phi$ is low, multiple equilibria can obtain for some intermediate values of $\alpha$ (case [ii]). This happens because, with risk neutrality, portfolio choice reacts to prices only through discrete jumps, while the effect of prices on wealth is continuous. Consider again the thought experiment where initially all agents agree on real rates and then some are replaced by highinterest types. For high $\alpha$, bond demand is due to high-interest agents, whose wealth is increasing in the house price. At the same time, the supply of bonds comes in part from borrowing by low-interest agents. Locally, the latter also increases with the house price, as the borrowing constraint is relaxed. Both supply and demand are locally not sensitive to the interest rate. Markets can then clear both at a high house price, which give rises to high supply and demand, and at a low house price, which gives rise to low supply and demand. ${ }^{11}$ Because this multiplicity is due to auxiliary assumptions and does not affect the main effect we emphasize-house-price booms occur for intermediate values of $\alpha$-we do not use it in our interpretation of the following model.

\section{Proof of Proposition 1}

Proposition 1 establishes the existence of cutoffs for price and interest rates in any equilibrium. Under the additional assumption $\phi>\phi^{*}=h_{0} b /$ $\left(b_{0}+y\right)$, part (c, i) of Proposition $2 *$ shows uniqueness, the special form of the cutoffs, as well as the monotonicity of the interest rate and the hump shape of the house price.

\section{Proof of Proposition 2}

Part (a) is the same as part (a) of Proposition 2*. Part (b) follows from part (a) of Proposition 1*.

Part (c) follows from part (c, i) of Proposition $2^{*}$.

11. If $\varphi$ is higher, bond supply becomes more sensitive to the interest rate and equilibrium is unique. The same is true if the exogenous bond supply $\bar{b}$ is smaller; in fact, $\varphi^{*}=0$ if $\bar{b}=0$. In addition, equilibrium is unique if bond demand becomes less sensitive to the house price as $\bar{h}_{0}$ falls; we have $\varphi^{*}=0$ also if $\bar{h}_{0}=0$. 


\section{References}

Asness, Clifford. 2003. Fight the Fed model: The relationship between future returns and stock and bond market yields. Journal of Portfolio Management 30 (1): $11-24$.

Basak, Suleyman, and Hongjun Yan. 2005. Equilibrium asset prices and investor behavior in the presence of money illusion. London Business School and Yale School of Management, Working Paper.

Brunnermeier, Markus, and Christian Julliard. 2006. Money illusion and housing frenzies. NBER Working Paper no. 12810. Cambridge, MA: National Bureau of Economic Research, December.

Campbell, John Y., and Tuomo Vuolteenaho. 2004. Inflation illusion and stock prices. American Economic Review 94 (2): 19-23.

Cohen, Randolph B., Christopher Polk, and Tuomo Vuolteenaho. 2005. Money illusion in the stock market: The Modigliani-Cohn hypothesis. Quarterly Journal of Economics 120 (2): 639-68.

Doepke, Matthias, and Martin Schneider. 2006. Inflation and the redistribution of nominal wealth. Journal of Political Economy 114 (6): 1069-97.

Feldstein, Martin. 1980. Inflation and the stock market. American Economic Review 70 (5): 839-47.

Grandmont, Jean-Michel. 1977. Temporary general equilibrium. Econometrica 45 (3): 535-72.

Kiyotaki, Nobuhiro, and John Moore. 1997. Credit cycles. Journal of Political Economy 105 (2): 211-48.

Miller, Edward M. 1977. Risk, uncertainty, and divergence of opinion. Journal of Finance 32 (4): 1151-68.

Modigliani, Franco, and Richard Cohn. 1979. Inflation, rational valuation, and the market. Financial Analysts Journal 35 (2): 24-44.

Piazzesi, Monika, and Martin Schneider. 2006. Inflation and the price of real assets. University of Chicago and New York University, Working Paper.

Piazzesi, Monika, Martin Schneider, and Selale Tuzel. 2007. Housing, consumption and asset pricing. Journal of Financial Economics 83 (3): 531-69.

Ritter, Jay R., and Richard S. Warr. 2002. The decline of inflation and the bull market of 1982-1999. Journal of Financial and Quantitative Analysis 37 (1): 29-61.

Sharpe, Steven A. 2002. Reexamining stock valuation and inflation: The implications of analysts' earnings forecasts. Review of Economics and Statistics 84 (4): 632-48.

Summers, Lawrence H. 1983. The nonadjustment of nominal interest rates: A study of the Fisher effect. In Symposium in honor of Arthur Okun, ed. James Tobin, 201-41. Washington, DC: Brookings Institution.

\section{Comment Markus K. Brunnermeier}

The fact that the house price-rent ratio - a real measure of house price fundamentals - covaries with the nominal interest rate rather than the real in-

Markus K. Brunnermeier is a professor of economics at Princeton University, and a research associate of the National Bureau of Economic Research. 
terest rate is one of the many puzzles in real estate economics. Increases in the nominal interest rate, which may be completely caused by increases in inflation, depress the house price-rent ratio.

A similar negative correlation between inflation and stock prices prompted Modigliani and Cohn (1979) to conjecture that investors are prone to money illusion: they confuse nominal and real interest rates. When that is the case, investors mistakenly discount real future cash flows with the nominal interest rate (or, alternatively, ignore the fact that cash flows tend to grow in nominal terms as inflation rises). Consequently, the price-earnings ratio of stocks negatively comoves with inflation.

Initially, Modigliani and Cohn's money illusion hypothesis did not seem to apply to the housing market since - as Summers (1983) pointed outin the early 1970s, house prices were high even though inflation was rising. However, over a longer time series, there seems to be clear evidence that inflation depresses the house price-rent ratio even after controlling for fundamental factors that determine house prices (see Brunnermeier and Julliard 2008). This naturally leads to the question: what was different in the United States in the early 1970s.

The authors of this chapter provide a fresh perspective on this puzzle. They argue that money illusion can also explain house-price movements in the 1970s because it is not the level of inflation that matters, but the level of disagreement on inflation between rational investors and investors who suffer from money illusion. As inflation rises, rational households would like to short long-term nominal bonds, that is, borrow money (if the nominal rate does not adjust fully). However, in order to do so, they have to buy real estate as collateral. The authors argue that this mechanism led to an increase in housing demand by rational investors in the 1970s. This is in contrast to the late 1990s, when investors that were prone to money illusion boosted demand for housing.

To make this point precisely, the authors propose a very tractable twoperiod model. Agents derive utility from a single consumption good in both periods. Because agents' utility is linear, we can alternatively think of a model in which consumption only occurs in the last period, but households can "store" wealth for one period with a storage return of $1 / \beta$. In addition to storage, agents can transfer wealth in two ways. They can buy a bond that pays a real interest rate of $R / \pi$ or, alternatively, they can buy real estate. For simplicity, the authors consider housing as pure investment good and abstract from any service flow housing provides. House prices in period one are exogenously fixed to be the constant $p^{\prime}$.

In summary, in a frictionless world, agents have three ways to transfer wealth from period zero to the consumption period one. (See table 4C.1.)

Of course, in a world without frictions and homogeneous beliefs, noarbitrage guarantees that $R / \pi=1 / \beta$ and $p=\beta p^{\prime}$.

To make the model interesting, the authors introduce heterogeneous be- 
Payoff matrix: Possible wealth transfers from time $t=0$ to time $t=1$.

\begin{tabular}{lcc}
\hline & $t=0$ & $t=1$ \\
\hline Storage (analogy) & $-\beta$ & +1 \\
Bond & -1 & $+R / \pi$ \\
Housing & $-p$ & $+p^{\prime}$ \\
\hline
\end{tabular}

liefs about the real bond return, $R / \pi$. Rational agents have correct beliefs, while agents that are prone to money illusion have a distorted view of the real interest rate. They believe that inflation is always at some benchmark level, for example, 4 percent.

The heterogeneity in beliefs about the real interest rate leads to trading activity in the bond market. Whenever investors with money illusion underestimate the real interest rate, they sell the bond, while rational investors buy it. Without any further assumptions, investors' risk-neutrality would imply that they trade an infinite amount of bonds, and the housing market would be a complete side show.

What makes the model interesting are two constraints: (1) a collateral constraint that implies that one can only short bonds (borrow money) if one owns a house as collateral and (2) a short-sale constraint for housing. ${ }^{1}$ When inflation is low, money illusion investors underestimate the real interest rate and buy houses because they seem relatively cheap, while rational investors cannot short-sell houses. This is the standard effect of money illusion also studied in Brunnermeier and Julliard (2008). On the other hand, when inflation is high, investors that suffer from money illusion mistakenly think that the real interest is high and buy bonds. Rational investors realize that the bond price is too high and want to short it. In order to do so, they have to buy houses as a collateral. This, together with the shorting restrictions that irrational investors face, leads to excessively high house prices. The authors claim that this mechanism explains the increase in the house price-rent ratio in the 1970s. My comments are the following:

\section{Inflation Disagreement or Violation of Fisher Equation}

What makes this analysis different from earlier work on money illusion is that the effects are primarily driven by disagreement among rational investors and investors who are prone to money illusion. While an extreme form of money illusion in which agents never change their belief about inflation predicts a (downward sloping) monotonic relationship between inflation and the mispricing in the housing market, this chapter predicts a U-shaped pattern. Housing prices are excessively high whenever investors

1. While the plausibility of short-sale constraints is fiercely debated for the stock market (see, e.g., Battalio and Schultz 2006), it seems uncontroversial for the housing market. 
disagree about future inflation forecasts. This occurs when inflation is either very low (late 1990s) - because irrational investors predict inflation to be too high - but also when inflation is very high (as in 1970s) - because the irrational investors' inflation forecast is too low. To check the plausibility of this assumption, it seems natural to look at inflation forecast survey data. There are three main surveys of inflation forecasts. The Survey of Professional Forecasters and the Livingston Survey elicit inflation expectations of professional forecasters working for the financial industry. Unlike the former two, the Michigan Survey of Consumer Attitudes and Behavior focuses on individual households and, hence, seems the most appropriate one as this model attempts to capture not only rational forecasters but also households that are prone to money illusion. Mankiw, Reis, and Wolfers (2004) provide an interesting analysis of inflation expectations. Their study shows, among other things, that disagreement-measured by the interquartile range - slightly leads the median inflation expectation and steadily declines from 1983 onward, with the exception of a blip in the early 1990s. Overlaying the plot with the house price-rent ratio shows that the disagreement explanation of this chapter does a very good job for the 1970s, but is less convincing for the house-price frenzy that started in the late 1990s (see fig. 4C.1).

However, simply looking at disagreement measures of inflation forecasts does not do full justice to this model because money illusion can take on very subtle forms. It might very well be that individuals - when askedhave a good estimate of inflation, but nevertheless fail to distinguish between nominal and real mortgage interest rates. Put differently, it is quite plausible that money illusion reflects a failure of the Fisher equationagents may ignore that real interest rates are roughly equal nominal interest rates minus inflation - rather than a biased inflation forecast. Hence, with a slight reinterpretation, the authors' mechanism may still be compelling.

\section{An Alternative Hypothesis for 1970s}

Another unusual feature of the 1970s is that the house price-rent ratiounlike in other periods - negatively comoves with the real mortgage interest rate. The price-rent ratio in the 1970s is above its trend when real mortgage rates are low (or even negative) and below its trend when real mortgage rates are high. This observation is consistent with the following alternative hypothesis: a sharp increase in inflation alerts households such that they subsequently correctly take inflation effect into account and focus on the real interest rate. On the other hand, a gradual change in inflation can easily go by unnoticed by a fraction of households. This alternative hypothesis suggests that, in the 1970s, the hedging aspect of housing against inflation risk and especially the tax-deductability of mortgage interest payments were driving housing demand. The fact that nominal 


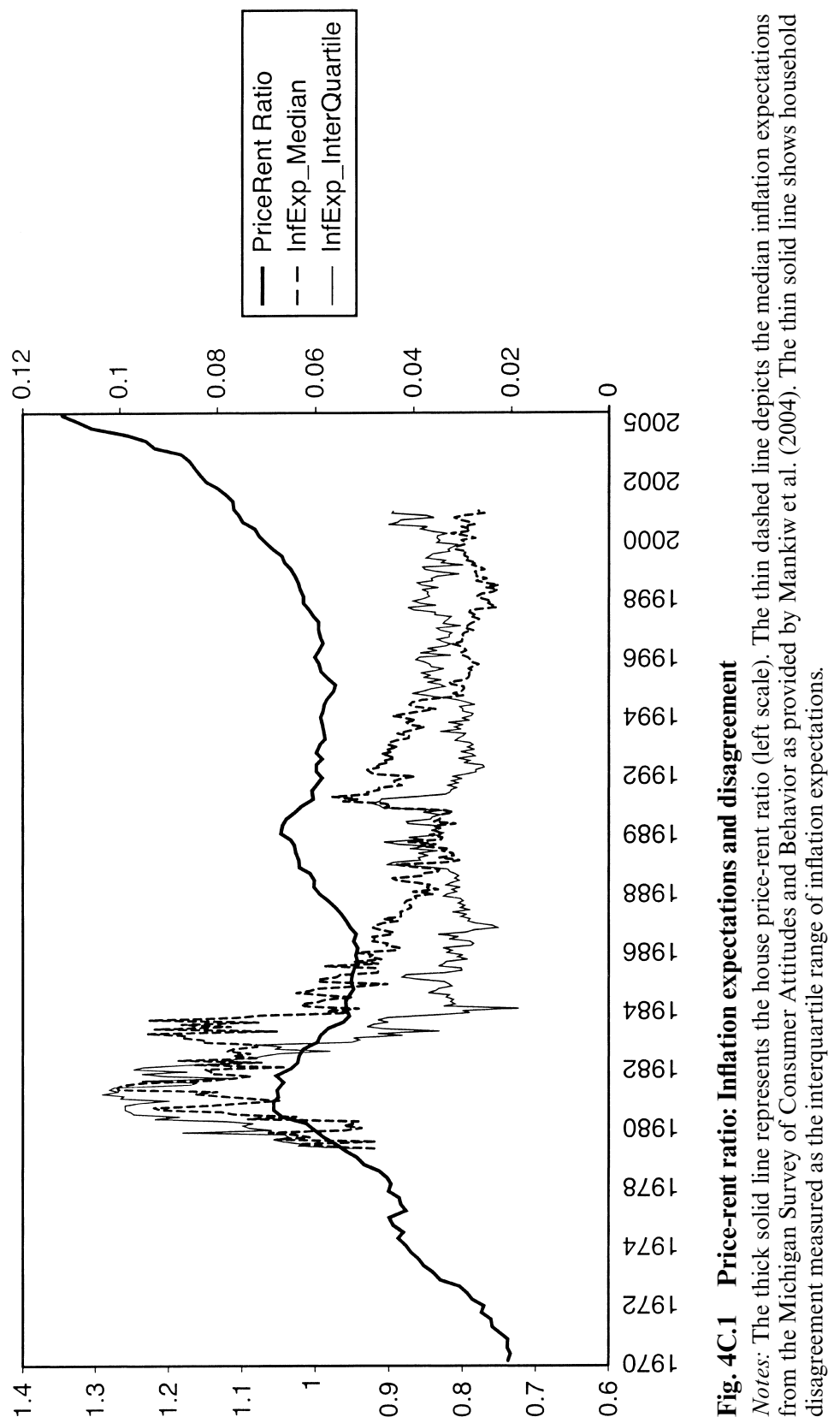


mortgage interest payments are tax-deductible creates a huge incentive to buy a house and borrow money when inflation is high, an effect that was widely discussed at that time. It is, therefore, not surprising that house prices boomed (as emphasized in Poterba [1984] and Titman [1982]). Note also that this alternative hypothesis would also square nicely with Amihud's (1996) finding that the Modigliani-Cohn hypothesis does not hold for the Israeli stock market. High inflation in Israel may have alerted investors to the difference between nominal and real interest rates.

\section{Loan-to-Value-Ratio}

When disagreement is high, that is, when either inflation is very high or fairly low, agents would be willing to leverage their housing investment more. One might, therefore, guess that the loan-to-value ratio should be higher in the 1970s and late 1990s. However, Japelli and Pagano (1989, 1994) and Almeida, Campello, and Liu (2006) document an average loanto-value ratio of 89 percent for the 1980 s, which exceeds the 80 percent value registered in both the 1970s and 1990s. Because there are many caveats attached to these numbers, a more elaborate study of real estate leverage would be desirable. Of course, it might also be that banks act rationally and limit credit whenever real estate is overpriced, therefore reducing the average loan-to-value ratio.

\section{Role of Intermediaries}

There are no intermediaries in the model, even though they play a significant role in the mortgage market. Their importance was even more pronounced in the 1970s, before mortgages were securitized. While in the model irrational investors take the other side of the mortgage contract in a high inflation environment, in the 1970s, the banking sector, especially thrifts, took on a large part of the inflation risk. As inflation spiked, banks seemed to have lost a large fraction of their value because they issued mortgages that were partially financed by short-term demand deposits (see, e.g., White 1991). Even though some thrifts were arguably poorly managed, I find it more plausible that professional bank managers were surprised by the inflation spikes and inadequately hedged rather than prone to money illusion.

\section{Possible Extensions}

The model could be extended in a variety of ways to gain further insights into the mechanism. Departing from the linear utility function specification would enrich the model in two ways. First, it would give housing a role as a hedge against inflation risk. Second, varying the elasticity of intertemporal substitution can cause interesting wealth and feedback effects. Another possibility to augment the model is to allow for disagreement about future house prices. The authors abstract from this by assuming that the future house price is fixed at $p^{\prime}$. If agents were to disagree about the fu- 
ture house price $p^{\prime}$, current house prices would also increase in this disagreement measure. The reasoning is analogous to Miller (1977): optimists push up house prices, while pessimists cannot push them back down because they face short-sale constraints.

Overall, the chapter provides a very interesting U-shaped relation between the price-rent ratio and inflation by combining money illusion and disagreement about inflation with realistic collateral constraints and shortsale constraint on housing. The authors' focus on disagreement about inflation forecasts provides a novel explanation of why we observed relatively high house prices in the 1970s when inflation was high.

\section{References}

Almeida, Heitor, Murillo Campello, and Crocker Liu. 2006. The financial accelerator: Evidence from international housing markets. Review of Finance 10 (3): 132.

Amihud, Yakov. 1996. Unexpected inflation and stock returns revisited-Evidence from Israel. Journal of Money, Credit, and Banking 28 (1): 22-33.

Battalio, Robert, and Paul Schultz. 2006. Options and bubbles. Journal of Finance 61 (5): 2071-2102.

Brunnermeier, Markus K., and Christian Julliard. 2008. Money illusion and housing frenzies. Review of Financial Studies 21 (8): 135-80.

Jappelli, Tullio, and Marco Pagano. 1989. Consumption and capital market imperfections: An international comparison. American Economic Review 79(5): 1088-1105.

- 1994. Savings, growth, and liquidity constraints. Quarterly Journal of Economics 109 (1): 83-109.

Mankiw, N. Gregory, Ricardo Reis, and Justin Wolfers. 2004. Disagreement about inflation expectations. In NBER macroeconomic annual 2003, ed. Mark Gertler and Kenneth Rogoff, 209-48. Cambridge, MA: MIT Press.

Miller, Edward M. 1977. Risk, uncertainty, and divergence of opinion. Journal of Finance 32 (4): 1151-68.

Modigliani, Franco, and Richard Cohn. 1979. Inflation, rational valuation and the market. Financial Analysis Journal 37 (3): 24-44.

Poterba, James M. 1984. Tax subsidies to owner-occupied housing: An asset market approach. Quarterly Journal of Economics 99 (4): 729-52.

Summers, Lawrence $\mathrm{H}$. The nonadjustment of nominal interest rates: A study of the Fisher effect. In Symposium in honor of Arthur Okun, ed. James Tobin, 20141, Washington DC: Brookings Institution.

Titman, Sheridan. 1982. The effects of anticipated inflation on housing market equilibrium. Journal of Finance 37 (3): 827-42.

White, Lawrence. 1991. The $S \& L$ debacle. New York: Oxford University Press.

\section{Discussion Summary}

Martin Schneider responded to Brunnermeier's discussion by saying that the authors had wanted to incorporate heterogeneity because it appeared that nominal interest rates respond strongly to inflation. In a framework 
with a representative agent subject to inflation illusion, this would not be the case. Schneider also argued that it was not possible to identify the proportion of people subject to inflation illusion from surveys. Finally, he said that the results of the quantitative model were included in the chapter primarily to convince people that the effects highlighted in the chapter could be quantitatively important.

Stephen G. Cecchetti said that he was surprised that high nominal interest rates were associated with high house prices because mortgage qualifications related to nominal rates: that is, $\varphi$, the parameter that drives the results when people disagree, was decreasing in the nominal interest rate. Schneider replied that he thought that financial innovation had helped to amplify this effect.

Martin Feldstein said that he thought the tax treatment of mortgage interest payments is an important factor for house prices. The government focuses on nominal interest rates for the purpose of deductions, so when inflation is high, the after-tax real interest rate decreases. This, he suggested, drives much of the variation in house prices. Piazzesi agreed and said that the authors were addressing the issue in a companion paper.

Donald L. Kohn said that if inflation illusion were responsible for the housing-price boom, one might expect to see less of a boom in inflationtargeting countries than in the United States. But that was not the case. $\mathrm{He}$ suggested that this cast doubt on the chapter's hypothesis and that it might be instead that irrational investors in housing merely extrapolate past capital gains forward. If the argument of the chapter were correct, however, it would make it harder for monetary policymakers to respond to houseprice bubbles because changes in interest rates and inflation would worsen disagreement among investors and increase housing demand.

Marvin Goodfriend responded to Kohn that there is an identification problem: central banks may choose to target inflation because they lack credibility. In this case, disagreement about inflation may be just as severe in inflation-targeting countries. Goodfriend also said that more flexible monetary policy, with multiple goals, may lead the central bank to lose control of investor beliefs about inflation and that the chapter provides an example of a real distortion that can arise from such a loss of control.

Simon Gilchrist said that it would be important to look for direct evidence for the increased dispersion of beliefs relied upon by this model and others like it.

John C. Williams pointed out that the house price-rent ratio had increased greatly in recent years and that this run-up was not uniform over the United States but rather was concentrated on the coasts. If so, the model asked us to believe that people on the coasts were most subject to illusion. Schneider replied that he thought that supply considerations could explain this fact: in the center of the country, supply expanded to meet demand, while on the coasts, supply was fixed. 
Andrew Levin said that the reason that the original inflation illusion literature had not focused on housing prices was because the tax effect was so obvious: there was a huge benefit to housing investors from the fact that tax deductions were based on nominal rates. Schneider agreed that the tax effect was first-order. But he argued that the disagreement effect was also first-order; in the authors' other paper, they found that the two effects were of comparable magnitudes. Brunnermeier said that his paper with Julliard finds a substantial effect of money illusion on housing prices, and this effect can be rationalized through the tax channel because money illusion and interest rate deductability have opposite effects on housing prices. 